\title{
Guidelines for pilot study on introducing pay-for-performance (P4P) approach to increase utilization of maternal, newborn and child health services in Bangladesh
}

Directorate General of Health Services (DGHS)

Population Council

UNICEF

Follow this and additional works at: https://knowledgecommons.popcouncil.org/departments_sbsr-rh

Part of the Demography, Population, and Ecology Commons, Family, Life Course, and Society Commons, Health Policy Commons, International Public Health Commons, Maternal and Child Health Commons, Public Health Education and Promotion Commons, and the Women's Health Commons How does access to this work benefit you? Let us know!

\section{Recommended Citation}

Directorate General of Health Services (DGHS), Population Council, and UNICEF. 2010. "Guidelines for pilot study on introducing pay-for-performance (P4P) approach to increase utilization of maternal, newborn and child health services in Bangladesh." Dhaka: DGHS, Population Council, and UNICEF. 


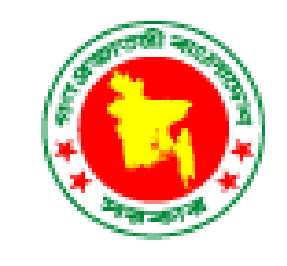

Guidelines for Pilot Study on Introducing Pay-For-Performance (P4P) Approach to Increase Utilization of Maternal, Newborn and Child Health Services in Bangladesh

\section{Pay-for-Performance Incentive Guideline P4P and/or Coupon Committee Guideline Quality Assurance Groups Guideline Coupon for Clients Guideline}

Directorate General of Health Services (DGHS), Bangladesh Population Council, Bangladesh

UNICEF Bangladesh

October 2010 
Guidelines for Pilot Study on Introducing Pay-For-Performance (P4P) Approach to Increase Utilization of Maternal, Newborn and Child Health Services in Bangladesh

\section{Pay-for-Performance Incentive Guideline P4P and/or Coupon Committee Guideline Quality Assurance Groups Guideline Coupon for Clients Guideline}

Additional information about Guidelines may be obtained from:

Directorate General of Health Services (DGHS)

Ministry of Health and Family Welfare

DGHS Bhaban, Mohakhali, Dhaka 1212

Phone: 8811741
Population Council

South \& East Asis-Bangladesh Office

House CES (B) 21, Road 118

Gulshan, Dhaka, Bangladesh

Phone: 880-2-8821227, 8826657

Fax: 880-2-8823127

UNICEF Bangladesh

BSL Office Complex, 1 Minto Road, Dhaka 1000, Bangladesh

Phone: 8852266

Fax:(880-2) 9335641-2

Suggested citation:

Directorate General of Health Services (DGHS), Population Council, and UNICEF. "Guidelines for introducing pay-for-performance (P4P) approach and subsidized coupons to increase utilization of maternal, newborn and child health services in Bangladesh." Dhaka, Bangladesh: DGHS, Population Council, and UNICEF. 


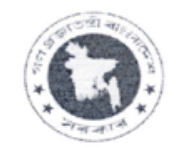

Government of the People's Republic of Bangladesh Directorate General of Health Services, Mohakhali, Dhaka

Memo no. DGHS/PHC/ESD/RH/2010/614: Date: $10 / 10 / 10$

Sub: Approval of guidelines for providing pay-for-performance to providers, formation of $\mathrm{P} 4 \mathrm{P}$ and/or coupon committees, formation of quality assurance groups and distribution of coupons to clients under P4P pilot project

This is to inform you that under the leadership of Director General of Health Services (DGHS), Population Council in collaboration with James P. Grant School of Public Health, BRAC University and with the financial and technical assistance from UNICEF is testing a pilot study titled "Introducing PayFor-Performance (P4P) Approach to Increase Utilization of Maternal, Newborn and Child Health Services in Bangladesh" in Gaibandha, Jamalpur and Kurigram districts in Bangladesh. From each district, four facilities - one District Hospital and three Upazila Health Complexes - have been selected for the P4P project. Under Jamalpur district, District Hospital and Upazila Health Complexes of Islampur, Melandah and Bakshiganj will receive the interventions. From Gaibandha, District Hospital and Shagahata, Sunderganj and Fulchhari Upazila Health Complexes have been included in the project. Under Kurigram district, the District Hospital and Upazila Health Complexes of Nageswari, Bhurungamari and Chilmari have been selected for the project.

Under the leadership of the DGHS, a total of four policy level and consensus building workshops with both national and local level program managers and service providers were organized in March to May 2010 to identify mechanism for introducing P4P approach for increasing utilization of maternal, newborn and child health services in Bangladesh. Based on the findings of the workshops and considering the local context, four guidelines have been developed for the P4P pilot project for: (i) providing pay-forperformance to providers; (ii) formation of P4P and/or Coupon Committee; (iii) formation of Quality Assurance Group; and (iv) distribution of coupons to clients. These guidelines are duly approved by the Directorate General of Health Services and will remain effective during the P4P pilot project's intervention period.

A.B.M. Jahangir Alam

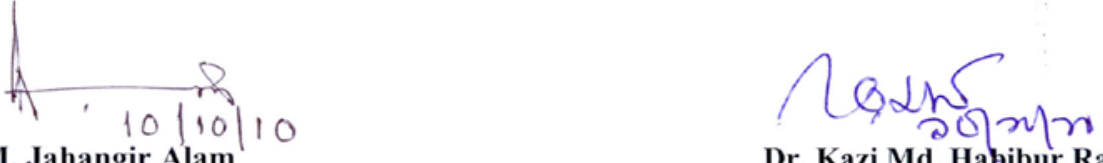

Director PHC \& Line Director ESD, DGHS

Dr. Kazi Md. Habibur Rahman

Program Manager, RH, DGHS

Memo no. DGHS/PHC/ESD/RH

1. Director General of Health Services

2. Office record

Enc: Guidelines for Providing Pay-For-Performance to Providers, Formation of P4P and/or Coupon Committees, Formation of Quality Assurance Groups, Distribution of Coupons to Clients for Increasing Utilization of Maternal, Newborn and Child Health Services in Bangladesh 


\section{Abbreviations}

$\begin{array}{ll}\text { AMTSL } & \text { Active Management of Third Stage Labor } \\ \text { AUFPO } & \text { Assistant Upazila Family Planning Officer } \\ \text { BMA } & \text { Bangladesh Medical Association } \\ \text { BEmONC } & \text { Basic Emergency Obstetric and Newborn Care } \\ \text { CEmONC } & \text { Comprehensive Emergency Obstetric and Newborn Care } \\ \text { DCM } & \text { Drugs, Consumables and Maintenance } \\ \text { DGFP } & \text { Directorate General of Family Planning } \\ \text { DGHS } & \text { Directorate General of Health Services } \\ \text { DSF } & \text { Demand-Side Financing } \\ \text { ECP } & \text { Emergency Contraceptive Pill } \\ \text { EmONC } & \text { Emergency Obstetric and Newborn Care } \\ \text { EPI } & \text { Expanded Program on Immunization } \\ \text { FWA } & \text { Family Welfare Assistant } \\ \text { GOB } & \text { Government of Bangladesh } \\ \text { HA } & \text { Health Assistant } \\ \text { IUD } & \text { Intra-Uterine Device } \\ \text { MLSS } & \text { Member of Lower Subordinate Services } \\ \text { MNCH } & \text { Maternal, Newborn and Child Health } \\ \text { MNH } & \text { Maternal and Neonatal Health } \\ \text { NGO } & \text { Non-governmental Organization } \\ \text { OCP } & \text { Oral Contraceptive Pill } \\ \text { OGSB } & \text { Obstetrics and Gynecological Society of Bangladesh } \\ \text { P4P } & \text { Pay-for-Performance } \\ \text { PNC } & \text { Postnatal Care } \\ \text { PPH } & \text { Postpartum Hemorrhage } \\ \text { QAG } & \text { Quality Assurance Group } \\ \text { QAT } & \text { Quality Assurance Team } \\ \text { QOC } & \text { Quality of Care } \\ \text { RMO } & \text { Resident Medical Officer } \\ \text { UFPO } & \text { Upazila Family Planning Officer } \\ \text { UHC } & \text { Upazila Health Complex } \\ \text { UHFPO } & \text { Upazila Health and Family Planning Officer } \\ & \end{array}$




\section{Table of Contents}

\section{Appendixes}

Appendix A: Quality Assurance Group's qualitative monitoring tool 25

Appendix B: Quality Assurance Group’s quantitative monitoring tool 41

Tables

Table B.1. P4P scheme implementing facilities 3

Table B.2. Target Beneficiaries (Management) at District and Upazila 4

Table B.3. Target Beneficiaries (Service) at District Hospital 5

Table B.4. Target Beneficiaries (Service) at Upazila Health Complex 6

Table B.5. Key areas for performance measurement through quantitative and 8 qualitative indicators

Table C.1. District Hospital pay-for-performance and/or coupon committee 11

Table C.2. Upazila health Complex pay-for-performance and/or coupon committee 11

Table D.1. QAG facility visitation schedule 17

Table E.1. Types of services for which beneficiaries will receive coupon 19

Table E.2. Transportation coupon amount according to types of service 20

\section{Figures}

Figures B.1. P4P model for providers to receive incentives for performance 9

Figures D.1. Quality assurance cycle 15

Figures E.1. Coupon distribution and payment of cash, medicines and diagnostic 23 services to the poor pregnant women and mothers against coupons 


\section{A. Background}

Maternal mortality ratio (MMR) in Bangladesh is one of the highest in the world. The country is far away from achieving the Millennium Development Goal (MDG) target of reducing MMR to 143 by the year 2015. There are also concerns relating to neonatal mortality rate, which has declined only modestly from 52 to 37 per 1,000 live births ${ }^{1}$. Reducing under-five children's mortality rate from 65 to 50 per 1,000 live births remains an MDG priority in Bangladesh ${ }^{2}$. The key challenges in reducing maternal, neonatal and under-five child mortality include lack of access, and inadequate and poor quality of maternal, newborn and child health $(\mathrm{MNCH})$ services. Although the Government of Bangladesh (GoB) has developed a comprehensive $\mathrm{MNCH}$ service delivery infrastructure from grassroots to higher levels, there is a significant underutilization of the existing capacity due to both demand- and supply side barriers. On the supply side, shortages of qualified staff, essential drugs and supplies, coupled with administrative delays and clinical mismanagement are key barriers to improve quality MNCH care services. The most important supply-side challenge in Bangladesh is the shortage and sub-optimal performance of service providers ${ }^{3}$.

The Population Council (the Council) has launched a pilot study to test two Pay-for-Performance (P4P) strategies to improve MNCH services in Bangladesh. The study will be implemented as a part of the two on-going MNCH and MNH projects of the United Nations Children Fund (UNICEF) implemented by the Directorate General of Health Services (DGHS), Government of Bangladesh. The P4P study has been included as a human resource innovation project under the operational plan of the Government of Bangladesh for the year 2010 and 2011. BRAC and Care Bangladesh are the two existing partners of the MNCH and MNH projects while the James P. Grant School of Public Health (JPGSPH) of BRAC University has been collaborating with the Council.

The Government of Bangladesh has been implementing demand-side-financing (DSF) scheme to reduce the MMR in selected Upazilas. The P4P is an alternate model. The first P4P strategy will introduce incentives tied with performance for motivating service providers to improve the quantity as well as quality of services; and will enable the poor pregnant women, and mothers of newborns and under-five children to access services by reducing their out-of-pocket costs for medicines, transportation and incidental costs by providing subsidized coupons. The second strategy will constitute a P4P scheme for providers only. In order to implement the P4P approach and coupon distribution, the study outlined formation of facility-based P4P and/or Coupon Committee and Quality Assurance Group (QAG). In order to enable the facilities to maintain the service quality, a small amount of fund, namely, Drug, Consumables and Maintenance (DCM) Fund will be provided to the P4P and/or Coupon Committee.

Guidelines to provide incentives to providers, distribute coupons, and form $\mathrm{P} 4 \mathrm{P}$ and/or Coupon Committees and QAGs, a total of five policy level and consensus building workshops with both national and local level program managers and service providers were organized under the leadership of the DGHS from March to August 2010. Based on the findings of the workshops, which were actively participated by the stakeholders, four guidelines for implementation of performance based incentives to providers, formation of the P4P Committees and/or Coupon

\footnotetext{
${ }^{1}$ Bangladesh Demographic and Health Survey 2007

2 Bangladesh Maternal Mortality Survey 2001

3 Talukder and Rob in "Strengthening voice and accountability in the health sector"
} 
Committee; formation of the QAGs; and distribution and realization of coupons have been developed. The P4P and/or Coupon Committees and QAGs are integral factors to implement the $\mathrm{P} 4 \mathrm{P}$ approach and coupon for the poor pregnant women, newborns and children. The guidelines

have been developed in consideration of the local context and sustainability in case of nationwide replication in the country.

The guidelines will come into effect upon receiving approval from the DGHS, Ministry of Health and Family Welfare, Government of Bangladesh; and remain effective during the pilot project's intervention period.

\section{B. Pay-for-Performance Incentive Guideline}

This guideline gives a brief overview of the pay-for-performance concept for facility-based beneficiaries including providers and field workers, distinction between the DSF and P4P, prerequisites for introducing the $\mathrm{P} 4 \mathrm{P}$ scheme, facilities under the $\mathrm{P} 4 \mathrm{P}$ scheme; beneficiaries, and benefit ratio. It elaborates on (i) indicators and performance measurement of the institution; (ii), payment rules; and (iii) reimbursement mechanism.

Formation of $\mathrm{P} 4 \mathrm{P}$ committees and QAGs is an integral part of the P4P project implementation. The guidelines for formation of the P4P committees and QAGs are also delineated in C and D sections.

\section{B.1. Definition of Pay-for-Performance}

P4P has been defined as financial incentive to reward service providers for meeting certain performance measures as a way to address underutilization of services and ensure quality of care. Under this study, financial incentive will be provided to the facility-based $\mathrm{MNCH}$ teams based on achieving the institutional target of $\mathrm{MNCH}$ services. Field workers will receive incentive for coupon distribution and making referrals on each case.

\section{B.2. Difference between the DSF and P4P scheme}

As reflected in the names, DSF finances the demand-side whereas pay-for-performance finances the supply-side factors to improve outcomes. The P4P allows paying an incentive for achieving at least a benchmark level of performance to providers as a team to improve the quantity as well as the quality of services they deliver. DSF is about transfer of purchasing power to the poor or targeted population to receive services directly from the accredited providers of their choice while the providers are reimbursed for their services from a special fund against the vouchers of services. P4P approach is tied with both quality and quantity of services while the DSF provides incentive to providers based on quantity of services.

\section{B.3. Prerequisites of the P4P scheme}

As the P4P scheme targets to motivate the providers to provide quality of services, this requires providers stationed in the facility, and providers to have functional health facilities with necessary supplies, equipment and training. In order to measure the performance to reward the providers, quality assurance system needs to be in place. More specifically, a quality assurance group independent of the facility needs to measure the services to (i) accredit the facilities that provide minimum acceptable level of $\mathrm{MNCH}$ care before introducing the P4P scheme; (ii) ensure routine measurement of performance mechanism in place; and (iii) timely and appropriate incentive payment mechanism in place. 


\section{B.4. Facilities under the P4P scheme}

The P4P scheme will be implemented in a total of 12 health facilities in Gaibandha, Kurigram ${ }^{4}$ and Jamalpur districts. The facilities include 3 District Hospitals, and 9 Upazila Health Complexes (UHC). Six of the facilities provide comprehensive emergency obstetric care services (CEmONC); and the remaining 6 facilities provide basic emergency obstetric care services (CEmONC).

Table B.1. P4P scheme implementing facilities

\begin{tabular}{|c|c|c|c|c|c|}
\hline \multicolumn{2}{|c|}{ Gaibandha } & \multicolumn{2}{|c|}{ Kurigram } & \multicolumn{2}{|c|}{ Jamalpur } \\
\hline Facility & $\begin{array}{l}\text { Type of } \\
\text { Facility }\end{array}$ & Facility & $\begin{array}{l}\text { Type of } \\
\text { Facility }\end{array}$ & Facility & $\begin{array}{l}\text { Type of } \\
\text { Facility }\end{array}$ \\
\hline $\begin{array}{l}\text { - Gaibandha } \\
\text { District Hospital }\end{array}$ & CEmONC & $\begin{array}{ll}\text { - } & \text { Kurigram } \\
\text { District } \\
\text { Hospital }\end{array}$ & CEmONC & $\begin{array}{l}\text { - Jamalpur } \\
\text { District } \\
\text { Hospital }\end{array}$ & CEmONC \\
\hline - Sundargonj UHC & CEmONC & $\begin{array}{l}\text { - Nageswari } \\
\text { UHC }\end{array}$ & CEmONC & $\begin{array}{l}\text { - *Islampur } \\
\text { UHC }\end{array}$ & CEmONC \\
\hline - Fulchari UHC & BEmONC & $\begin{array}{l}\text { - Bhurungamari } \\
\text { UHC }\end{array}$ & BEmONC & $\begin{array}{l}\text { - Melandah } \\
\text { UHC }\end{array}$ & $\mathrm{BEmONC}$ \\
\hline - Saghata UHC & BEmONC & $\begin{array}{l}\text { - Chilmary } \\
\text { UHC }\end{array}$ & BEmONC & $\begin{array}{l}\text { - Bakshiganj } \\
\text { UHC }\end{array}$ & BEmONC \\
\hline
\end{tabular}

${ }^{4}$ Nilphamari was initially selected as one of the pilot districts. The DGHS in discussion with UNICEF has replaced Nilphamari with Kurigram in July 2010. 


\section{B.5. Beneficiaries, level of effort and the benefit ratio}

Quality of care and utilization of $\mathrm{MNCH}$ services depend on a well coordinated team at the facility, which consists of managers, direct and indirect service providers of the $\mathrm{MNCH}$ services as well as support staff. The team spirit, dedication and efficiency are crucial to improve the utilization of MNCH services.

Besides the QAG, each facility will have quality assurance teams (QATs) formed for each of the service units with the providers and support staff of the respective facilities. For instance, separate QATs may be formed for Operation Theater, labor room, indoor and outdoor services. The QATs will meet at least monthly to ensure the quality of care. The QAGs in the quarterly visits may generate team spirit and provide guidance, but providing the standard quality of care to the pregnant women, neonates and under-five children will depend on the leadership of the facility-based QATs.

Thus, managers, direct and indirect service providers of the $\mathrm{MNCH}$ services and support staff of the selected facilities will receive incentives based on achieving the institutional performance target according to their level of effort.

The facility level MNCH teams are also part of the Quality Assurance Teams (QATs) who will ensure the quality of care.

In addition to the facility based beneficiaries, the field workers including Family Welfare Assistants (FWAs), Health Assistants (HA) and NGO volunteers/workers will receive Taka 50 for each successful MNCH complications related referral cases.

Tables B.2, B.3 and B.4 depict the target beneficiaries, level of effort and benefit ratio of the District Hospital and Upazila Health Complex.

Table B.2. Target Beneficiaries (Management) at District and Upazila Level

\begin{tabular}{lrr}
\hline Target beneficiaries & Level of effort (\%) & Benefit ratio \\
\hline Managers at District level & 100 & 100 \\
Civil Surgeon/Superintendent & & \\
Deputy Director, Family Planning & & \\
& & 100 \\
Managers at Upazila level & 100 & \\
Upazila Health and Family Planning Officer (UHFPO) & & \\
Upazila Family Planning Officer (UFPO)/ & & \\
Assistant Upazila Family Planning Officer (AUFPO) & & \\
\hline
\end{tabular}


Table B.3. Target Beneficiaries (Service) at District Hospital

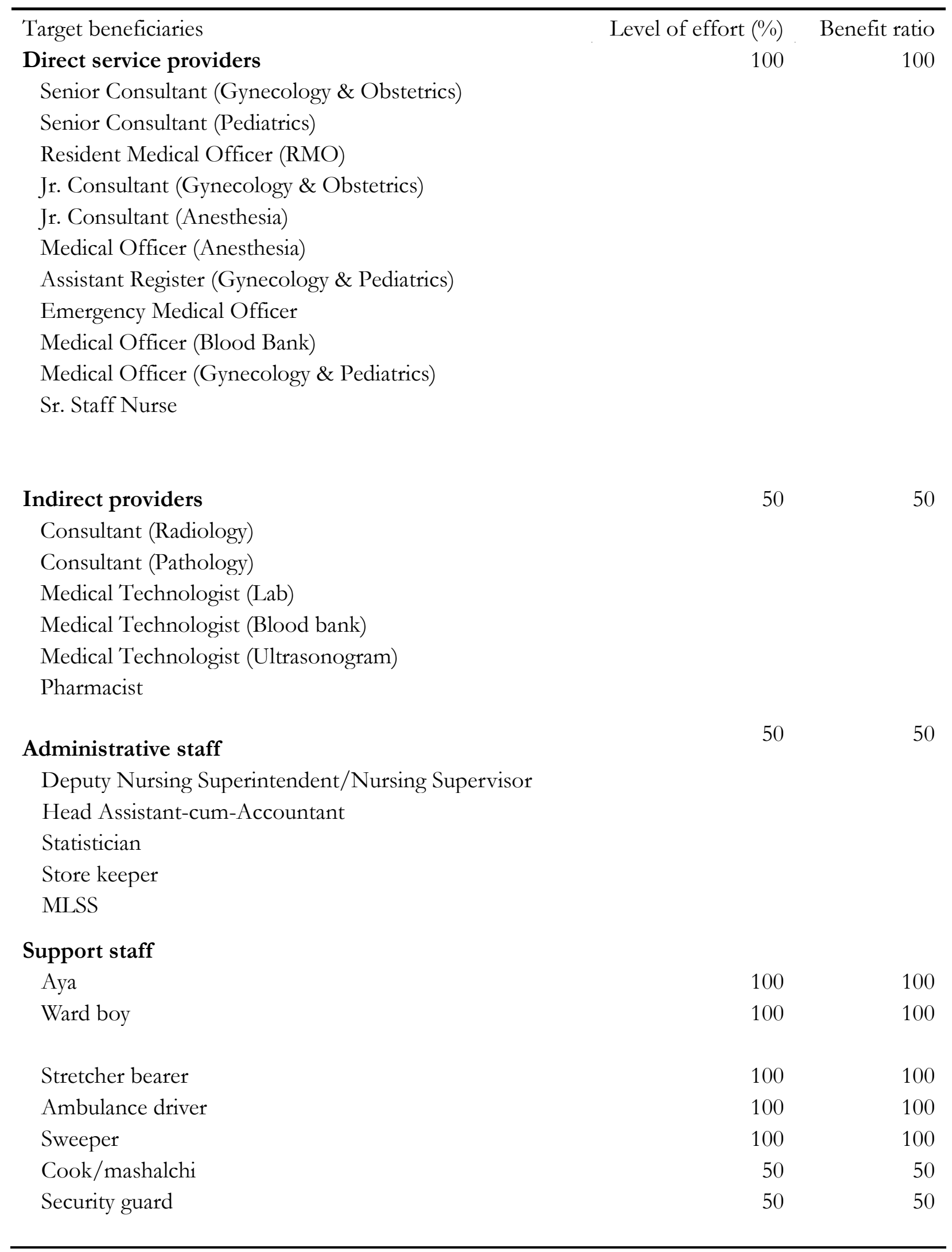


Table B.4. Target Beneficiaries (Service) at Upazila Health Complex

\section{Target beneficiaries}

Direct providers

Level of effort $(\%)$

100

Benefit ratio

Jr. Consultant (Gynecology \& Obstetric)

Jr. Consultant (Pediatrics)

Jr. Consultant (Anesthesia)/Medical Officer (Anesthesia)

Medical Officer (MCH-FP)

Resident Medical Officer

Medical Officer

Medical Officer (Disease Control)*

Sr. Staff Nurse

Assistant Family Welfare Officer/Sr. Family Welfare

Visitor

Family Welfare Visitor

Medical Assistant

Indirect providers

50

50

Pathologist

Medical Technologist (Ultrasonogram)

Medical Technologist (Lab)

EPI Technician

Pharmacist

Administrative staff

50

50

Head Assistant-cum-Accountant

Statistician

Store keeper

MLSS

\section{Support staff}

Aya

100

100

100

100

100

50

50

Ward boy

Stretcher bearer

100

Ambulance driver

100

Sweeper

100

Cook/mashalchi

100

Security guard

50

* Medical Officer (Disease Control) is to be included only if s/he provides services to the clients. 
The benefit ratio of the designated person(s) who will keep records, make payment against coupon, DCM and incentives, prepare fund request documents and expense report will be considered as 100\%. The field workers including Family Welfare Assistants (FWAs), Health Assistants (HA) and NGO volunteers/workers will receive Taka 50 for each successful MNCH complications related referral cases.

\section{B.6. Accreditation}

In response to request from the P4P committee, the QAGs will visit the facility to accredit and ensure that the facilities provide minimum acceptable level of MNCH care. The P4P scheme cannot be initiated, and facilities cannot be promoted in the communities unless the facilities are accredited by the QAG. Following an interactive consultation process, the QAGs will help the facilities to identify gaps, if any, and address the gaps either at the facility level or through assistance of the District Hospitals or the DGHS.

\section{B.7. Benchmark level, target and indicators}

Benchmark level: Facility wise benchmark and target level will be set because the catchment area and realities on the ground vary across facilities. In determining the benchmark level, the last three years performance can be considered. Benchmark level will be set in consultation with the QAG and the P4P committee during the first accreditation visit. A composite index will be calculated based on both the quantitative and qualitative indicators.

Target: The facility-based target will be set at standard achievable level. Two levels of targets will be set in consultation with the QAG and the P4P committee. For example, the first level of target can be $20 \%$ increase from the benchmark level while the second level of target can be $30 \%$ increase from the benchmark level of performance. In cases where the facility has reached the maximum attainable target in terms of quantity, the performance target can be set to increase quality of care in providing services.

Indicators: Qualitative and quantitative indicators will be considered in setting the benchmark, targets and measuring performance. A list of priority indicators has been identified based on the consensus building workshops at the national and district levels with stakeholders, and literature reviews of guidelines of World Health Organization, Government of Bangladesh, Obstetrics and Gynecological Society of Bangladesh, Operational Manual of Quality Assurance of Government of India, and Population Council's Frontiers in Reproductive Health Program manual. Two qualitative and quantitative monitoring tools have been developed, as depicted in Appendixes A and B. The P4P Committee will review the indicators while setting the benchmark and target in discussion with the QAG.

The areas of qualitative and quantitative indicators that will be used for accreditation and measuring the performance have been depicted in Table B.5. Qualitative indicators include input and process indicators; for instance, indicators under $\mathrm{A}$ to $\mathrm{E}$ are input indicators, which are invested in programs to process outputs, such as, antenatal care, delivery and postnatal care services in order to produce the outcomes of reduced morbidity and mortality. Indicators under $\mathrm{F}$ to $\mathrm{H}$ are process indicators while indicators from I onwards measure the outputs of the program in terms of quantity of services. 
Table B.5. Key areas for performance measurement through quantitative and qualitative indicators



\section{B.8. Incentive amount}

The service providers will be able to earn at least one-month basic salary as performance payment in a quarter of a year if the facility attains the first level of target. In case of achieving the second level of target, the providers will receive one and a balf months' basic salary as performance payment in a quarter. Besides, for referring complicated $\mathrm{MNCH}$ cases to the designated facility, the referees (field workers) will receive Taka 50 for each successful referral. The successful referral connotes receiving services by the referred client from the facility, which is to be documented with referral slips and registers.

\section{B.9. Disbursement of incentives}

The incentives will be disbursed by the P4P committees upon receiving approval from the QAG on achieving the quarterly target. The P4P committee will prepare and submit the certified list of the beneficiaries consisting of the MNCH teams along with the incentive amount in the beginning of the quarter. The P4P committee will calculate incentives in terms of achieving both first and second level of targets. The proposed incentive amount will be supported by the last month's salary statement of the beneficiaries certified by the head of the institution and validated by the $\mathrm{P} 4 \mathrm{P}$ committee. In order to manage the incentive amount, the P4P committee will open a Bank Account in the name of the institution followed by the Committee name (e.g. Islampur Upazila Health Complex P4P Committee). The bank account will be jointly operated by the Civil Surgeon/Superintendent and Resident Medical Officer for the District Hospitals, and the UHFPO and Resident Medical Officer for the Upazila Health Complexes.

Upon opening the bank account, the P4P Committee will request advance fund to the Council against the projected expense for facility based beneficiaries' incentive and field workers' referral cases. Upon receiving the advance request along with necessary documents, the Council will make arrangement to transfer the advance amount to the P4P Committee's bank account. The Council, in consultation with an Audit Firm, will also provide formats of necessary receipts, ledgers, and expense account statements to the facility designated person to ensure appropriate adjustment of the 
advance against the actual expenses of the incentive payment. The incentives to the facility based providers are paid quarterly based on achieving the quarterly target but the facilities will settle the advance with the Council every month through their monthly expense account submitted along with necessary and appropriate supporting documents.

In the $1^{\text {st }}$ week of the following month of the quarter, the QAG will visit the facility to assess the facility's MNCH performance; and report on target achievement. The P4P committee, based on the performance measured, will calculate and disburse incentive to the $\mathrm{MNCH}$ teams by issuing Account Payee bank checks to each beneficiary of the facility-based MNCH team. The P4P Committee will submit the monthly expense account to the Council towards adjusting the advance account with original receipts and supporting documents. The advance account will be settled based on certification from the audit firm.

The pay-for-performance for providers to get incentive according to institutional performance of $\mathrm{MNCH}$ services in a quarter is depicted in Figure B.1.

Figure B.1. P4P model for providers to receive incentives for performance

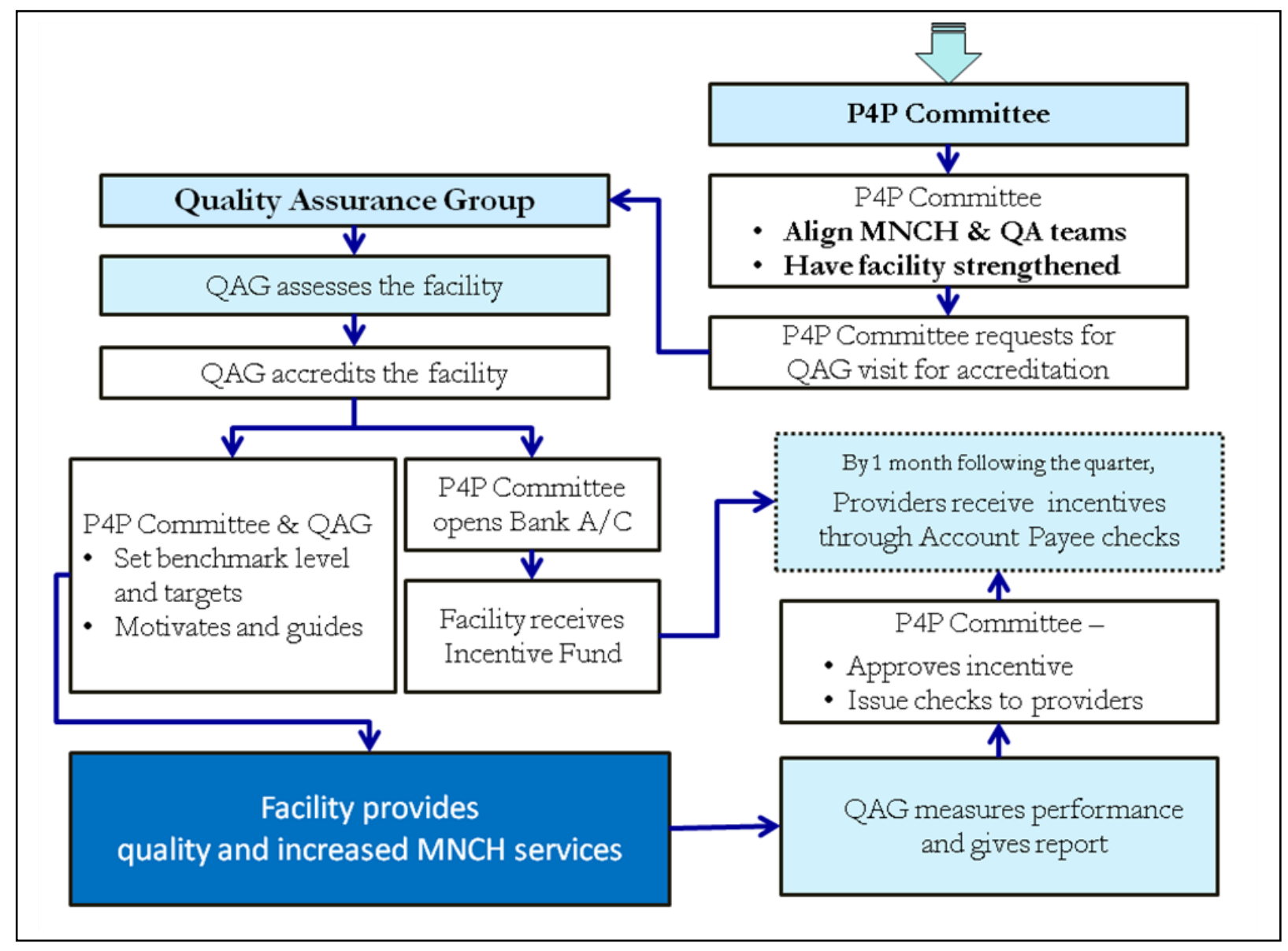




\section{Pay-for-Performance and/or Coupon Committee Guideline}

A total of 12 institution-based P4P and/or Coupon Committees will be formed in the selected facilities in order to strengthen the facility, set benchmark and performance targets, manage providers incentive, coupon distribution and utilization, to manage the facility-based Drugs, Consumables and Maintenance (DCM) Fund, and to facilitate the P4P study activities.

The P4P committee will align the MNCH teams and QATs. The QATs will identify the gaps and needs of the facility to provide quality MNCH services, and then let the DGHS through the P4P committee to know about the shortfall in human resources and drugs and other supply needs.

Upon facility strengthening, the P4P committee will request the QAG to assess the facility's MNCH service care for accrediting them with regard to capacity to provide basic and/or emergency obstetric, newborn and under- five child care services. The QAG will support, guide and motivate the P4P Committee and the QATs to improve their MNCH services and quality of care. The P4P committee will work actively with the QATs to help them identify problems and find out solutions. The P4P committee in consultation with the QAG and QATs will set their benchmark and pragmatic first and second levels of quarterly targets.

In order to manage the incentive, coupon and DCM fund, the P4P committee will open a Bank Account in the name of the institution followed by the Committee name (e.g. Islampur Upazila Health Complex P4P Committee). The bank account will be jointly operated by the Civil Surgeon/Superintendent and Resident Medical Officer for the District Hospitals, and the UHFPO and Resident Medical Officer for the Upazila Health Complexes. The committees in Jamalpur district will be known as "P4P Committee" while the committees in Gaibandha and Kurigram districts will be known as "P4P and Coupon Committee". District and Upazila level Hospital Management Committees will oversee, discuss and guide the respective P4P and/or Coupon committees.

The P4P and/or Coupon committee will assess the projected expenses for a month and request advance fund to the Council to meet the expenses. The committee will settle the advance by submitting the expense account with original receipts and necessary documents against facility beneficiaries and field workers' incentive, coupon and DCM fund every month. The advance account will be adjusted upon receiving the original receipts and certification of appropriateness of the books and receipts by the Population Council appointed Audit Firm.

Each facility will receive DCM fund of Tk.1,000.00 to Tk.5,000.00 each month during the intervention period for meeting expenses for consumables and facility maintenance. The needs will be assessed by the P4P committee in consultation with the QATs. Purchasing of any essential drugs, which are usually provided by the GoB under the DCM will require approval from the Consultant/MOs (Obs \& Gyne \& Pediatrics). The request for the projected DCM fund expenditure will be made by the P4P committee to the Population Council; and it will be settled every month. The P4P committee will manage the Coupon fund as per the Coupon guideline mentioned in section E. 
Tables C.1 and C.2 depict the structures of the P4P and/or Coupon Committees for the District Hospital and Upazila Health Complex, respectively.

\section{Table C.1. District Hospital Pay-for-Performance and/or Coupon Committee}
1. Civil Surgeon/Superintendant
Chairperson
2. Deputy Director-Family Planning/
Member
Assistant Director (Clinical Contraception)
3. Nursing Supervisor
Member
4. An NGO representative (BRAC/CARE)
Member
5. A BMA representative
Member
6. Resident Medical Officer
Member-Secretary

\section{Table C.2. Upazila Health Complex Pay-for-Performance and/or Coupon Committee}

1. Upazila Health and Family Planning Officer

Chairperson

2. Upazila Family Planning Officer/ Assistant Upazila Family Planning Officer

3. Nursing Supervisor

Member

4. An NGO representative (BRAC/CARE)

Member

5. A representative from Upazila Parishad

Member

6. Resident Medical Officer

Member

Member-Secretary

\section{Terms of Reference of the P4P and/or Coupon Committees}

1. Coordinate with the DGHS to ensure adequate and necessary supply of drugs, consumables, equipment and trained human resources, as necessary to run the facility's EmONC services.

2. Align the facility-based MNCH care team and QATs for each quarter. Display the names of the members of the MNCH and QATs at the facility.

3. Issue request for receiving accreditation from the QAG through the DGHS.

4. Establish the benchmark level and the first and second level of targets in discussion with the QAG, facility based QATs and the third party (the Council). Make the MNCH and QATs aware of the targets; and display the benchmark and targets prominently at the facility.

5. Facilitate the QAG and the Council to measure quantitative and qualitative performance using the facility's service statistics and facility visitation.

6. Orient the facility's MNCH care team including the QATs, and provide necessary support and guidance to improve the institutional $\mathrm{MNCH}$ performance in terms of quantity and quality.

7. Open the P4P and/or Coupon Committee's bank account. For Gaibandha and Kurigram, the name of the bank account will be P4P and Coupon Committee preceded by name of the institution. For Jamalpur, name of the bank account will be P4P Committee preceded by the name of the institution.

8. Sign an agreement with the Council about receiving fund for the P4P project and incur expenses following the standard accounting practices, approved guidelines and procedures put forth in the financial mechanism manual. Assess and request the monthly advance to the Council by submitting an advance request form. The advance request should be made in broad 
headings of (i) incentive payment to facility based $\mathrm{MNCH}$ beneficiaries, (ii) incentive payment to field workers for coupon distribution and/or referral, (iii) incurring expenses against Drugs, Consumables and Maintenance fund, (iv) payment against transportation coupon to the coupon beneficiaries, (v) acquisition of medicines for distribution among the coupon beneficiaries, (vi) payment to the diagnostic centers for providing diagnostic services to the coupon beneficiaries, and (vii) payment against incidental costs to the coupon beneficiaries. Upon receiving the advance request, the Council will arrange transfer of the fund to the P4P and/or Coupon Committee's bank account.

9. The comprehensive EmONC health facilities will identify qualified diagnostic centers that may be recommended for the patients with coupons to have emergency diagnostic services that are unavailable at the facility; and carry out contract with the diagnostic facilities to reimburse them upon providing services on monthly basis.

10. Approve of incentive distribution to providers/beneficiaries' bank accounts based on institutional performance, providers' presence, and referrals made by the field workers.

11. Approve of coupon distribution (in Gaibandha and Kurigram) according to the list of poor pregnant women and poor mothers of neonates and under-five children submitted by the respective FWAs, HAs and NGO field workers, and certified by the union level health and family planning committees.

12. Provide incentives by issuing Account Payee checks as incentives to the providers; coupon distributors/field workers, and diagnostic service facilities.

13. Arrange for providing medicines, and cash for transportation and incidental costs to coupon beneficiaries at the facilities.

14. Monitor financial reimbursement to the P4P scheme beneficiaries and expenses made for the DCM fund (in Jamalpur, Gaibandha and Kurigram); and coupon beneficiaries (in Gaibandha and Kurigram only).

15. Manage and keep appropriate records, vouchers and supporting documents of the facility beneficiaries and field workers' incentive, the transportation, medicine/diagnostic, and incidental coupons, payment to diagnostic facilities, and the DCM Funds.

16. Provide the lists of incentive and coupon beneficiaries, and diagnostic facilities certified by the head of the institution and validated by the P4P and/or Coupon committee while requesting the advance fund request to the Council.

17. Settle the advance received monthly by submitting the expense account along with the original receipts and supporting documents against facility beneficiaries and field workers' incentive, coupon and DCM fund to the Council. The advance will be adjusted upon receiving the original receipts and certification of appropriateness of the books and receipts by Audit Firm appointed by the Council.

18. Take measures to ensure smooth fund flow and prevent fraud and misappropriation of fund. For achieving this goal, the committee will cooperate with the Council and its appointed Audit Firm in establishing and practicing sound financial mechanism with regard to incentive disbursement, coupon payment, medicine acquisition and distribution, payment for the prescribed diagnostic services and incurring expenses against DCM fund. In case of anomaly or fraudulent activities, the $\mathrm{P} 4 \mathrm{P}$ and/or Coupon Committee will take corrective measures immediately, as advised by the DGHS and audit firm. 
19. Meet at least once a month to review the performance of the facility and (coupon distribution in Gaibandha and Kurigram), and take appropriate measures. If necessary, the P4P committee may meet more frequently.

20. Facilitate the Council's monitoring and evaluation activities.

\section{Quality Assurance Group Guideline}

This guideline gives a brief overview of concept of the quality of care and quality assurance, discusses the QAGs, purpose and schedule of the QAG visits, scope of work of the QAGs, Quality of Care indicators, and tools for accreditation and assessing the EmONC facilities. The quality assurance tools include QAG Facility Visitation Schedule (Table D.1), qualitative and quantitative indicators (Appendixes- A and B), and QAG Report with Composite Index calculation.

\section{D.1. Quality of Care}

Quality of Care (QOC) concept was developed by the Council in mid-eighties, which outlined both technical and interpersonal aspects of the care of family planning services ${ }^{5,6}$. The QOC framework was later adapted in quality assessment and improvement in broader settings and services.

The Agency for Healthcare Research \& Quality (AHRQ) defines quality healthcare by "Doing the right thing, at the right time, for the right person, and having the best possible result". ${ }^{7}$

World Health Organization defines quality as "proper performance (according to standards) of interventions that are known to be safe, that are affordable to the society up questions, and have ability to procure an impact on mortality, morbidity, disability and malnutrition." 8

The Institute of Medicine defines quality health care as "treatment and care that is:

- Safe. Treatment helps patients and does not cause harm.

- Effective. Research shows that treatments have positive (good) results.

- Patient-centered. Healthcare providers (doctors, nurses, and others) treat all patients with respect. This means taking into account each patient's values about health and quality of life.

- Timely. Patients get the care they need at a time when it will do the most good.

- Efficient. Treatment does not waste doctors' or patients' money or time.

\footnotetext{
${ }^{5}$ Bruce Judith. 1990. "Fundamental elements of the quality of care: A simple framework," Studies in Family Planning 21(2): 61-91.

6 Jain Anrudh K., Judith Bruce, and Sushil Kumar. 1992. "Quality of services, programme efforts and fertility reduction," in Family Planning Programmes and Fertility, eds. James F. Philips and John A. Ross. Oxford: Clarendon Press, pp. 202-221.

${ }^{7}$ Quality Insights: Healthcare Performance in Massachusetts. Retrieved August, 2010 from http:/ /www.mhqp.org/quality/whatisquality.asp?nav $=030000$

${ }^{8}$ Roemer, M.I., and Aguilar, C.M. 1988. World Health Organization.
} 
- Equitable. Everyone is entitled to high quality healthcare. This includes men and women of all cultures, income, level of education, and social status." 9

\section{D.2. Quality Assurance}

Quality assurance (QA) can be defined as a "process of measuring quality, analyzing the deficiencies discovered, and taking action to improve performance followed by measuring quality again to determine whether improvement has been achieved. It is a systematic, cyclic activity using standards of measurement'. ${ }^{10}$

Varkey and colleagues ${ }^{11}$ opine that the quality assurance activities include accreditation of facilities, supervision of health provider \& workers, and other efforts to improve the performance of the health providers and the quality of health services. Continuous assessment of the quality of services by facilities is fundamental to any quality assurance program. It is known that unless monitoring and supervision are taken place regularly, people often resort to the simplest ways to getting outcomes. At times these outcomes do not necessarily correspond to the ultimate and intermediate goals of health systems and hence do not lead to client's satisfaction.

The quality of health care in all health centers is an issue of great importance to the GoB, because the government is committed to achieve sustainable improvement in the health, nutrition, and reproductive health including family planning of the people of the country. Quality assurance in Health and Population Sector Program was initiated in 1998 and has been continuing through the Health, Nutrition and Population Sector Program of 2003-2011.

With a goal of generating and supporting a "culture of quality consciousness," the GoB quality assurance program ${ }^{12}$ takes the slogan "doing the right thing right, right away" and states the following four quality assurance characteristics encompassing the clients, providers and managers-

- Focus on clients

- Focus on system and processes

- Focus on team approach; and

- Focus on data for decision making.

The Directorate General of Health Services outlines dimensions of quality in terms of effectiveness, efficiency, technical competence, safety, accessibility (geographical, economic, social/cultural, organizational, linguist access), interpersonal relations, continuity of care according to need without interruption or disruption, and amenities.

${ }^{9}$ Quality Insights: Healthcare Performance in Massachusetts. Retrieved August, 2010 from http://www.mhqp.org/quality/whatisquality.asp?nav $=030000$

${ }^{10}$ Lori DiPrete Brown et al. in "Quality Assurance of health care in developing countries"

${ }^{11}$ Varkey, Khan, Agarwal, Sharma. 2006. District Quality Assurance Program for RH services.

${ }^{12}$ Directorate General of Health Services, Government of Bangladesh. Training Module (Revised) for Upazila Health Complex under HNPSP (July 2003- June 2011). 
Quality Assurance is a systematic process, which can be explained in a Quality Assurance cycle ${ }^{13}$ consisting of the 10 steps.

\section{Figure D.1. Quality Assurance Cycle}

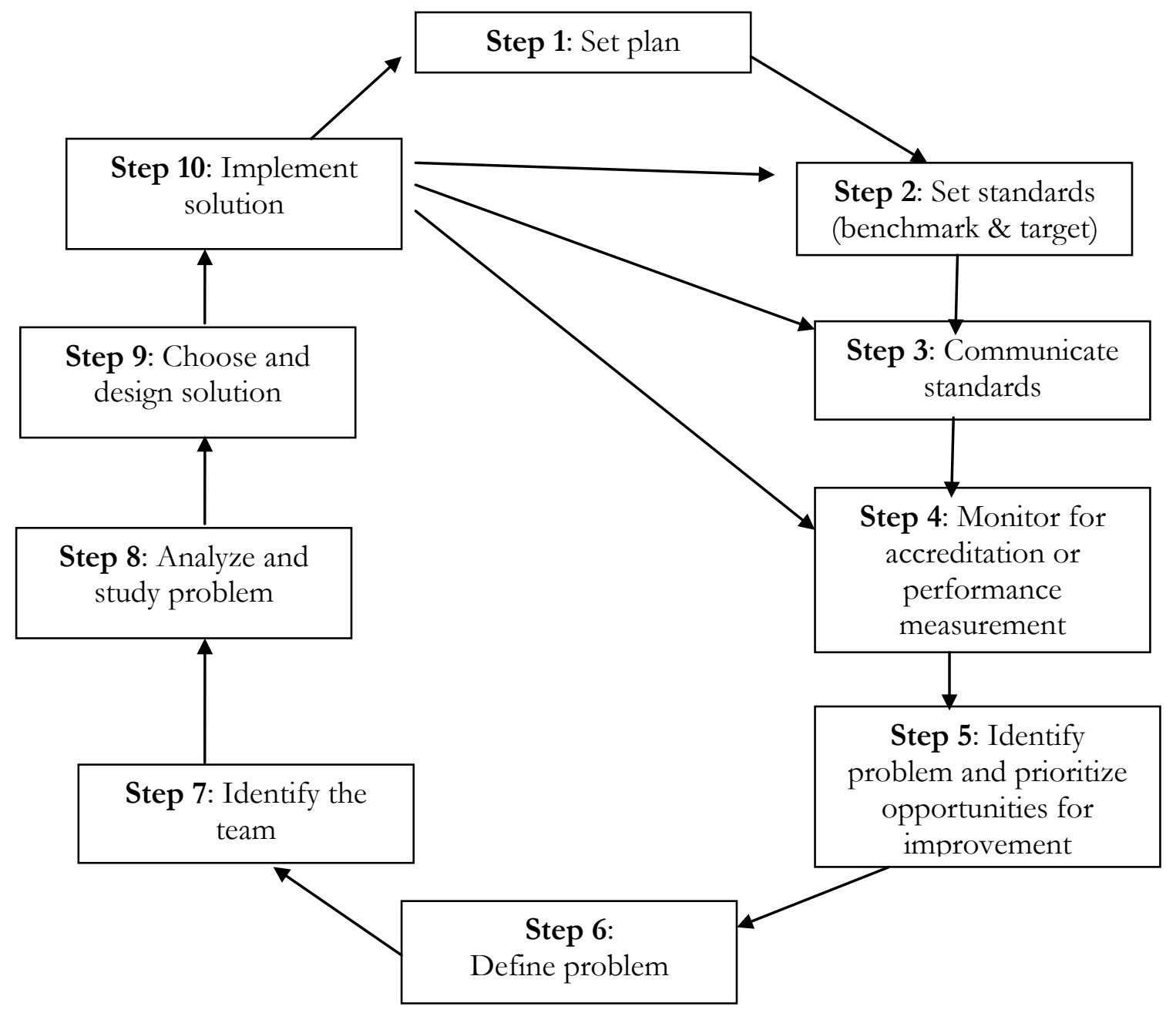

${ }^{13}$ Directorate General of Health Services, Government of Bangladesh. Standard Operational Procedure Guideline for District and Upazila Health Complex under HNPSP (2003-2011). 


\section{D.3. Quality Assurance Groups}

Quality Assurance Groups will consist of a team of technical persons from nearby Medical College Hospitals, District Hospitals and professional bodies, which will provide systematic visits to health facilities to accredit and assess, and provide feedback for improving the quality of care of EmONC services. It is imperative that QAGs are formed within, not outside the public health systems, in order to ensure sustainability of the quality assurance in the long run.

There are three types of facilities- (i) District Hospital, (ii) Comprehensive Emergency Obstetric and Newborn Care Upazila Health Complexes (CEmONC UHCs), and (iii) Basic Obstetric and Newborn Care UHCs (BEmONC UHCs); therefore, three types of QAGs will be formed. The QAGs of DH, CEmONC UHC and BEmONC UHC will have six, five and four members, respectively. A total of 12 QAGs, one for each facility will be formed.

\section{Members of the QAG for the District Hospitals}

- One obstetrician, one anesthetist, and one pediatrician- from nearby Medical College Hospital (Rangpur Medical College Hospital for Gaibandha and Kurigram District Hospitals; and Mymensingh Medical College Hospital for Jamalpur District Hospital)

- A representative of the Obstetrical \& Gynecological Society of Bangladesh (OGSB) from the respective district

- Civil Surgeon/Superintendent of the respective District Hospital

- One representative from the Population Council/JPGSPH

\section{Members of the QAG for the CEmONC UHCs}

- One obstetrician, one anesthetist, and one pediatrician from the respective District Hospital or Medical College Hospital

- Upazila Health and Family Planning Officer of the respective Upazila Health Complex

- One representative from the Population Council/JPGSPH

\section{Members of the QAG for the BEmONC UHCs}

- One obstetrician and one pediatrician- from the respective District Hospital

- Upazila Health and Family Planning Officer of the respective Upazila Health Complex

- One representative from the Population Council/JPGSPH

Population Council will represent in the QAG teams of Gaibandha and Kurigram districts while JPGSPH will represent in the QAG teams of Jamalpur district.

\section{D.4. Purposes and Schedule of the Quality Assurance Group Visits}

There are two broad purposes of the QAG visits. The first one is to assess the facility readiness to provide quality emergency or basic obstetric, neonatal and under-five child care services for accreditation purpose. After confirmation on fulfillment of the minimum standard of quality of care of EmONC services, the P4P related intervention activities can be initiated. This assessment extends beyond problems identification, to verification of the problems, identification of correctable 
measures and providing supportive supervision for improvement. The second purpose is to assess and compare the performance relative to the last quarter's performance to assure that identified problems have been resolved and that no further problems have been engendered in the process.

Each of the 12 facilities will receive minimum 5 visits, one visit in each quarter. The first QAG visit will be made for the accreditation purpose during the preparatory phase of the study, while the later visits will be made to assess the performance in terms of quantity and quality of care. The QAG assessments will be used in calculation of performance measurement for payment of incentive under the P4P scheme. The visit schedule will be intimated to the facility administration in advance, as it requires full cooperation from the facility. A schedule of visit format is attached in Table D.1.

It is, however, expected that QAG visits will be continued even after the ending of the pilot project. The QAGs will use standard facility visitation checklist, which has been developed in discussion with the relevant stakeholders including managers and providers at the four national and district level workshops. The checklist has been kept simple in order to enable the QAGs to complete assessment of each facility within a short period of time.

Table D.1. QAG facility visitation schedule

\begin{tabular}{|c|c|c|c|c|c|c|}
\hline \multirow{3}{*}{$\begin{array}{l}\text { Name of } \\
\text { facility }\end{array}$} & \multirow{3}{*}{$\begin{array}{l}\text { Type of } \\
\text { facility }\end{array}$} & \multicolumn{5}{|c|}{ Date and Time of Quarterly QAG Visit } \\
\hline & & $1^{\text {st }}$ visit & $2^{\text {nd }}$ visit & $3^{\text {rd }}$ visit & $4^{\text {th }}$ visit & $5^{\text {th }}$ visit \\
\hline & & For accreditation & \multicolumn{4}{|c|}{ For performance review } \\
\hline $\begin{array}{l}\text { Gaibandha } \\
\text { District } \\
\text { Hospital }\end{array}$ & CEmONC & & & & & \\
\hline Sundargonj & CEmONC & & & & & \\
\hline Fulchari & BEmONC & & & & & \\
\hline Saghata & BEmONC & & & & & \\
\hline $\begin{array}{l}\text { Kurigram } \\
\text { District } \\
\text { Hospital }\end{array}$ & CEmONC & & & & & \\
\hline Nageswari & CEmONC & & & & & \\
\hline Bhurungamari & BEmONC & & & & & \\
\hline Chilmary & BEmONC & & & & & \\
\hline $\begin{array}{l}\text { Jamalpur } \\
\text { District } \\
\text { Hospital }\end{array}$ & CEmONC & & & & & \\
\hline Islampur* & CEmONC & & & & & \\
\hline Melandah & BEmONC & & & & & \\
\hline Bakshiganj & BEmONC & & & & & \\
\hline
\end{tabular}




\section{D.5. Scope of Work of the QAGs}

- Prepare visit schedules in discussion with the respective facility management, DGHS/DGFP, UNICEF, Population Council, and JPGSPH.

- Orientation and discussion among the team members with regard to the QAG visit's purpose and procedures; and active listening the problems faced by the facility from the P4P committee and the QATs of the facility.

- Carry out quarterly performance measurement visits to the designated health facility.

- Motivate and guide the facility-based P4P committee, quality assurance teams, and MNCH teams in improving the MNCH services, setting benchmark and quarterly target levels.

- Follow the approved QAG protocol to assess the facility for accreditation or performance assessment purpose.

- Prepare the facility visit report incorporating the findings; and feedback for improvement within the next week of the visit.

- Share the compiled findings with the P4P and/or Coupon Committee of the facility, DGHS and UNICEF.

- Carry out assessment of follow-up action in the subsequent visits.

\section{D.6. Coordination among the QAG members}

Population Council/JPGSPH will facilitate coordination among the QAG members with support from the DGHS. Population Council/JPGSPH will prepare the QAG visit reports. The QAG members will meet quarterly in the facility. They will first have an initial discussion among themselves in distributing the work among themselves; then they will follow the guideline to evaluate the facility. After completing the visit, the QAG will hold a debriefing meeting with the facility's quality assurance and $\mathrm{MNCH}$ teams.

\section{D.7. Indicators to be measured by the QAGs}

Based on the four consensus building workshops with stakeholders, and literature reviews of World Health Organization, GoB and other international quality assurance guidelines and documents, a list of priority indicators have been identified; and two qualitative and quantitative monitoring tools have been developed, as depicted in Appendixes A and B. The P4P Committee will review the indicators while pragmatically setting the benchmark and targets in discussion with the QAG. 


\section{E. Coupon Guideline}

This guideline gives a brief overview of concept of the coupon, beneficiaries of the coupon, types of the coupon, design, criteria of coupon beneficiaries, coupon distribution strategy, reimbursement against coupons, and coupon utilization and verification.

\section{E.1. Coupon}

A coupon, coupon card, or voucher is a token document against which one can either receive cash, kind or services. Coupon has been widely utilized to generate demand for health services to address the demand-side barriers. Under the P4P project, coupon will be distributed to encourage poor mothers to utilize the services for pregnancy, delivery, postpartum, newborn and under-five children's health care of the three selected upazilas of Gaibandha and Kurigram districts. Coupons will be provided only at the rural unions.

\section{E.2. Beneficiaries of the coupon}

- Poor pregnant women who will become pregnant and/or give birth to receive services during the project period;

- Neonates (babies less than 28 days old) of the poor mothers; and

- Under-five year children of the poor mothers.

As secondary beneficiaries, field workers will receive Taka 20 for coupon client identification, distributing the coupon and discussing the purposes and complications for which poor pregnant women, neonates and under-five children may utilize the coupon by visiting the designated health facilities. For distribution, the coupon distributor will receive Taka 20 for each coupon. For referring complicated $\mathrm{MNCH}$ cases to the designated facility, the field workers will receive Taka 50 for each successful MNCH complications related referral cases.

\section{E.3. Types of the coupon}

The coupon will be provided to the poor mothers to meet the transportation cost, incidental cost, and medicines/diagnostic services for pregnancy care, delivery, postpartum and complications management for the new-born and under-five children. Transportation and incidental costs will be distributed in cash while medicines will be provided against medicine coupon. Thus, each coupon will have three parts to meet: (i) transportation cost; (ii) incidental cost; and (iii) medicine/diagnostic cost. The poor women and their neonates and under-five children are eligible to receive coupon for the following health care services-

Table E.1. Types of services for which beneficiaries will receive coupon

\begin{tabular}{ll}
\hline Purpose & Frequency \\
\hline Antenatal care & 4 times \\
Pregnancy complications management & 1 time \\
Delivery & 1 time \\
Postnatal complications management and a follow up service & 2 times \\
Neonate's (less than 28 days olds) complications management and a follow & 2 times \\
up service & \\
Under-five child's complications management and a follow up service & 2 times
\end{tabular}

Note: Pregnancy complications management will also include safe abortion care, and post-abortion care services. 
Women who will visit health facilities for the above mentioned $\mathrm{MNCH}$ services will be eligible to receive transportation cost and medicines. Incidental costs will be given only for the patients who need to stay overnight in the facility. The details of the transportation, incidental and medicine/diagnostic coupons are discussed below.

Transportation coupon: Transportation cost is a major factor in making delay in seeking health care services from the facility, especially at the rural and char areas of Bangladesh. In order to enable the poor mothers to receive services especially for complications management, coupons will be provided to the pregnant mothers and mothers of the neonates and under-five children, as depicted in Table E.2.

Table E.2. Transportation coupon amount according to types of services

\begin{tabular}{|c|c|c|c|}
\hline \multicolumn{2}{|c|}{ Purpose } & \multirow{2}{*}{$\begin{array}{l}\text { Frequency } \\
4 \text { times }\end{array}$} & \multirow{2}{*}{$\begin{array}{l}\text { Amount per visit } \\
\text { (Taka) } \\
100\end{array}$} \\
\hline 1. & Antenatal care & & \\
\hline 2. & Pregnancy complications management & 1 time & $300-700$ \\
\hline 3. & Delivery & 1 time & $300-700$ \\
\hline 4. & $\begin{array}{l}\text { Postnatal complications management } \\
\text { and a follow-up service }\end{array}$ & 2 times & $300-700$ \\
\hline 5. & $\begin{array}{l}\text { Neonate's (less than } 28 \text { days olds) complications } \\
\text { management and a follow-up service }\end{array}$ & 2 times & $300-700$ \\
\hline 6. & $\begin{array}{l}\text { Under-five child's complications management } \\
\text { and a follow-up service }\end{array}$ & 2 times & $300-700$ \\
\hline
\end{tabular}

Note: The P4P and Coupon Committee will decide the amount of transport within the limit according to distance.

Incidental coupon: In case of hospitalization to receive $\mathrm{MNCH}$ care, poor clients often have to bear out-of-pocket expenses even at the public health facilities in Bangladesh. To address this problem and reduce out-of-pocket costs of the poor clients, the poor eligible clients will receive incidental cost to reduce their hospitalization cost in case of hospitalization. The client will receive Tk.100 per day; however, the maximum limit of incidental costs will be Tk.500. The amount of the incidental cost may be increased by the Resident Medical Officer upon receiving recommendation from the service providers (Gyne \& Obs, Anesthesia, Pediatrics) on case to case basis in exceptional cases, such as, post-operative infection and uncontrolled eclampsia, which may require longer duration stay at the hospital, and this amount will be limited to a maximum of Tk.1000. Incidental expenses incurred will be systematically recorded for auditing purpose. The Population Council appointed Audit Firm will make orientation to the committee and the coupon payment maker to keep standard and appropriate receipts and records for proper utilization of incidental coupon.

Medicines and diagnostic coupon: Usually every government facility has sufficient stock of medicines, which are distributed free of cost to the patients. Each facility will effectively utilize these medicines for all patients including the coupon holders. If there is not enough supply of the required medicines or if the coupon holder needs other medicines, then the client will receive the required medicines against the coupon. The P4P and Coupon committee will make the list of necessary medicines in consultation with the Consultants/MOs (Gyne \& Obs, Anesthesia, Pediatrics) for a month and acquire them from the market at a competitive price. The medicines will be distributed by the pharmacist upon producing the coupon coupled with the prescription. 
If a coupon holder needs compulsory investigations (for eclampsia or uncontrolled hemorrhage), which is not usually offered in the comprehensive EmONC facility, then the provider may recommend such diagnosis on case to case basis. In this case, the coupon holder may avail of the diagnostic test from the P4P and Coupon Committee's enlisted diagnostic facility. The P4P committee will make disbursements to the diagnostic facility within a month of providing such diagnostic services.

The Population Council appointed Audit Firm will make orientation to the committee, the coupon payment maker and the pharmacist to keep standard and appropriate receipts for medicine purchase; and records for proper utilization of medicine/diagnostic coupon.

\section{E.4. Design of coupon}

Each coupon or coupon card will have three parts on transportation cost, incidental cost and medicine/diagnostic test. Besides the card will hold information of the facilities with cell phone numbers and $\mathrm{MNCH}$ danger signs or services for which the coupon can be utilized. The mothers will receive coupon for receiving services for her as well as her neonate and under-five children. Mothers of under-five children, who are not currently pregnant and have no neonates, will receive coupon for complications management service of her under-five children only.

\section{E.5. Criteria of the coupon beneficiaries}

Coupon beneficiaries should be the permanent and rural residents of the rural unions of Nageswari, Bhurungamari, Chilmary Upazilas of Kurigram district and Saghata, Fulchari and Sundargonj Upazilas of Gaibandha district. The coupon beneficiaries' family should meet any of the following criteria-

- own less than 0.15 acres of family land

- monthly family income is less than taka four thousand

- no productive assets, such as, livestock, orchards, rickshaw, van, boat

- primary occupation of the major income earner is day-laborer.

Following the government policy, families with two or less children will be given preference in the selection process.

Family Welfare Assistants, Health Assistants and NGO field workers of the selected six upazilas who usually keep pregnant women's list in the villages will develop the list of the coupon beneficiaries. The union level Health and Family Planning Committees will verify the list of the poor women (who are eligible to receive coupons).

\section{E.6. Coupon distribution and referrals}

After preparation of the list, coupons will be distributed primarily through the field workers including Family Welfare Assistants, Health Assistants and/or NGO field workers. While distributing the coupon the field workers will clearly explain the ways and reasons for coupon utilization. The coupon distributors will receive Taka 20, for identifying the eligible coupon beneficiary, distributing the coupons and explaining the utilization of coupon cards, for each case. Each of the Coupon Distributors will keep lists of the women and mothers of under-five children who received coupons in the Coupon Distribution Register. S/he will refer the complicated cases to the facilities, and tally after utilization of the services against coupon in the register. For referring complicated MNCH cases to the designated facility, the referees (field workers) will receive Taka 50 
for each successful MNCH complications related referral cases. Coupon distribution will continue during the intervention period on rolling basis with a condition that the services against coupon will be available only until the end of the project's intervention period. Coupon distributors will distribute coupon against the approved coupon recipient list and issue a coupon distribution receipt. The coupon distribution receipt will be prepared in four sets- one for the distributor, one for the coupon recipient, one for the facility and one for the Council. Coupon distributors will receive incentive against coupon distribution through an account payee check every month against the coupon distribution receipts that have signature/thumb impression of the beneficiaries enlisted in the approved coupon beneficiary list. Payment against complicated MNCH referrals will be made upon receiving the referral receipt presented by the patients and signed by providers. Only the GoB and enlisted NGO volunteers/workers will receive incentives against referrals every month through account payee checks. Each referral receipt will be initiated by the referees, and be issued in four sets- one for the referee, one for the patient, one for the facility and one for the Council.

\section{E.7. Reimbursement to patients against coupons}

The coupon holder will become eligible to receive cash from the coupon payment maker; and medicine from the pharmacist against coupon upon receiving services from MNCH provider at the facility. Transportation cost will be paid on the same day while incidental coupon for each day's hospitalization will be paid in cash either on the following day or during discharge from the hospital. A designated coupon payment maker will be selected by the P4P and Coupon Committee amongst the indirect P4P incentive recipients, who will make reimbursement against coupons and distribute medicines at the facility. The coupon payment maker will make cash payment for transportation and incidental costs upon the beneficiary's producing the coupon card in which the provider will mention the services provided to the patient and the amount that need to be paid to the beneficiary. There will be a back-up person for making payment against coupon, who will ensure continuous cash distribution to the poor pregnant women or mothers of the neonates and under-five children. The essential medicines are usually offered by the public health facility at free of cost to the patients. However, in case of absence of any essential medicines recommended by the provider, the medicines may be made available to the coupon beneficiary by the Pharmacist. Upon disbursement of the medicines, the pharmacist will keep signature/thumb impression of the patient (pregnant women/mother) in the Medicine disbursement receipt prepared in three sets- one for the patient, one for the facility and one for the Council. The pharmacist will also keep an updated stock register against the acquisition and distribution of medicines to the coupon beneficiaries.

Regarding recommended diagnostic investigation from an outside facility, which is not usually available in the hospital/facility, the P4P committee will make a list of the diagnostic facilities in the vicinity of the facility. After being recommended by the designated provider, the facility will carry out the diagnostic test for the client against the produced coupon card. The diagnostic facility will be reimbursed for the tests offered to the coupon clients within a month of providing services.

The coupon payment maker will keep a signed receipt from the coupon beneficiary against any cash disbursement in three copies (the first copy for the recipient, the second copy for the facility/payment maker; and the third copy for the Population Council). The payment maker will also keep a Cash book against disbursement for transportation and incidental costs. Similarly the diagnostic facility will keep Diagnostic service receipts in four sets against services rendered to the coupon patients- one for their record, one for the client, one for the health facility and one for the Council. 
The Population Council will engage an Audit firm to orient the committees, the coupon payment makers, pharmacists and diagnostic facilities to make payment appropriately following the standard accounting practice.

The coupon distribution and payment of cash, medicines and diagnostic services to the poor pregnant women and mothers against coupons has been briefly depicted in Figure E.1.

Figure E.1. Coupon distribution and payment of cash, medicines and diagnostic services to the poor pregnant women and mothers against coupons

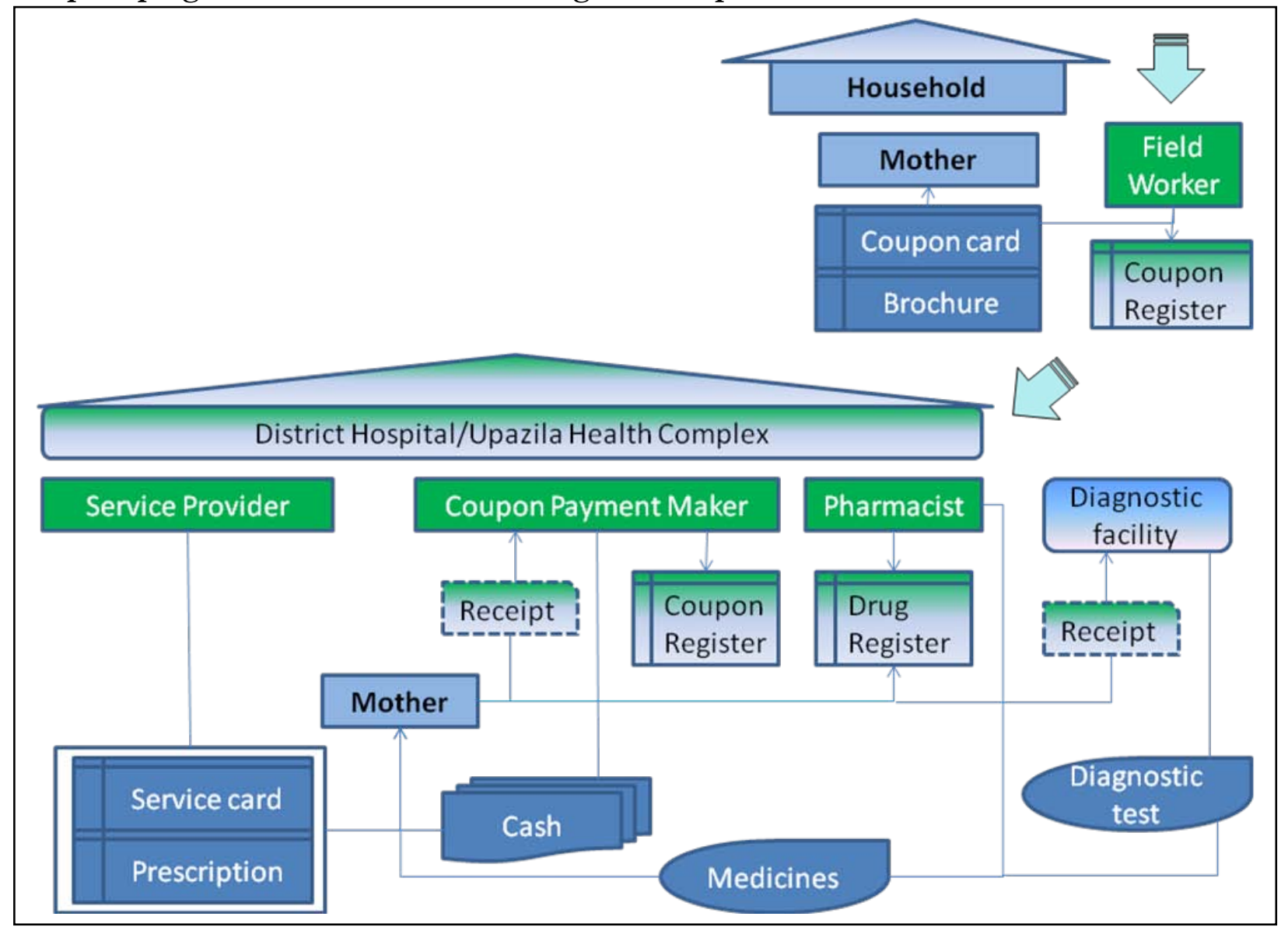

\section{E.8. Coupon utilization}

To encourage the utilization of the coupons, there will be continuous community mobilization by the government and NGO field workers. At the same time, community leaders including the Union Chairs and members and Union level health and family planning committee will take initiatives to inform the poor women to utilize the coupon in the defined intervention areas. In order to ensure utilization even in case of loss of a coupon card, duplicate card may be issued by the facility head or the Resident Medical Officer in discussion with the Coupon Distributor.

\section{E.9. Requisition and adjusting the provisional coupon expenses}

The P4P committee will assess the projected expenses for a month for coupons and request the fund to the Council to meet the expenses by submitting an advance request invoice signed by the appropriate authority. The invoice will include projected expenses for transport, medicines, 
diagnostics, incidental and coupon distribution cost. Upon receiving the advance request, the Council will arrange transferring money to the P4P and Coupon Committee's bank account. The P4P and Coupon Committee will settle the advance account every month by submitting the final invoice along with the original receipts and supporting documents. The advance will be adjusted upon receiving the receipts in original and certification of appropriateness of the books and receipts by the Population Council appointed Audit Firm.

\section{E.10. Coupon distribution and coupon utilization verification}

At the facility level, there will be (i) Coupon Distribution and Utilization registers, (ii) Drug Acquisition for Coupon holders and Distribution registers; (iii) Diagnostic service registers for Coupon holders; (iv) Payment for Coupon distribution and Referral Service registers for making payment to the field workers for coupon distribution and/or making successful referrals; and (v) Cash register.

The field workers will also maintain the Coupon Distribution, Utilization and Referral registers to keep track of coupon distribution, utilization of coupon and referrals made to the clients. Similarly, the Diagnostic facilities will keep a Diagnostic service register for keeping track of the services provided to the coupon holders.

All the original receipts will be provided to the Council for adjustment towards advance received against coupon related expenses.

The Population Council appointed audit firm will orient the committee and the relevant persons to ensure appropriate and standard maintenance of receipts, supporting documents and registers against coupon related expenses and adjustment of the advance account.

A total of 10 to 20 percent coupon users will be randomly interviewed by the Population Council appointed audit firms/staff to prevent fraudulent activities against coupon distribution and utilization. Similarly, the field workers and other diagnostic facilities will be interviewed to ensure proper utilization and distribution of funds.

In case of anomaly or fraudulent activities, the findings will be reported to the respective P4P and Coupon Committee and to the DGHS for taking immediate corrective measures.

The quality of care in receiving services by the coupon clients will be assessed from the exit client interviews and follow-up in-depth interviews by the Population Council researchers. 


\section{Appendix- A}

\section{Government of People's Republic of Bangladesh \\ Directorate General of Health Services}

$$
\text { Reproductive Health Program }
$$

\section{Quality Assurance Group (QAG) Visit Qualitative Monitoring Tool for}

Pilot Study on Introducing Pay-For-Performance (P4P) Approach to

Increase Utilization of Maternal, Newborn and Child Health Services in Bangladesh

Name of Health Facility:
Type of Facility: CEmONC_Lity Information
Distance from the District Hospital (kilometers):
Address and phone number of the Facility:
Name of the Head of the Facility:
Name, position and phone number of the person who coordinates the QAG visit:
Signature of the QAG Coordinator at the facility:

\begin{tabular}{|l|c|c|c|}
\hline \multicolumn{5}{|c|}{ Quality Assurance Group Information } \\
\hline Sl. & Name & Designation & Signature of the Members \\
\hline 1. & & & \\
3. & & & \\
4. & & & \\
5. & & & \\
6. & & \\
\hline \multicolumn{3}{|c|}{ Quality Assurance Group Visit Information } \\
\hline Date of current visit: Time started: \\
Date of last visit:
\end{tabular}




\section{QAG Facility Visiting Steps}

\begin{tabular}{|l|l|l|}
\hline STEPS & YES & NO \\
\hline $\begin{array}{l}\text { Discussion among the QAG members on the visiting procedures } \\
\text { and division of work }\end{array}$ & & \\
\hline $\begin{array}{l}\text { Briefly meet the facility-based quality assurance teams and the P4P } \\
\text { committee members }\end{array}$ & & \\
\hline - & & \\
\hline $\begin{array}{l}\text { Carrying out the monitoring according to the QAG checklist } \\
\text { about the findings }\end{array}$ & & \\
\hline $\begin{array}{l}\text { Actively listening from the P4P and QATs about their views on the } \\
\text { basic/emergency obstetric, newborn and child care readiness of the } \\
\text { facility }\end{array}$ & & \\
\hline $\begin{array}{l}\text { Motivate and offer specific suggestions to improve the quality of } \\
\text { care of MNCH services }\end{array}$ & & \\
\hline $\begin{array}{l}\text { Assist the P4P committee to set the first and second levels of } \\
\text { qualitative and quantitative targets relative to the benchmark }\end{array}$ & & \\
\hline
\end{tabular}

Suggestion for immediate action to improve the quality at the facility level:

Suggestion for immediate action to improve the quality for the higher levels, District Hospital for the UHCs and the DGHS:

\section{Remarks:}




\section{SECTION- A: PROVIDERS' AVAILABILITY AND MANAGEMENT COMMITTEES INCLUDING P4P AND QUALITY ASSURANCE TEAMS}

Table A.A. Qualitative indicators on providers' availability and facility management committees

\begin{tabular}{|c|c|c|c|c|c|}
\hline \multirow[t]{2}{*}{ S1 } & \multirow{2}{*}{$\begin{array}{l}\text { Indicators } \\
\text { (Fill in the score by asking questions) }\end{array}$} & \multicolumn{4}{|c|}{ Response Score } \\
\hline & & \multicolumn{2}{|r|}{3} & 2 & 0 \\
\hline \multicolumn{6}{|c|}{ Providers' availability } \\
\hline 1. & $\begin{array}{l}\text { Have at least- } 2 \text { Consultants or Medical Officers (MOs) } \\
\text { trained in Obstetrics and Gynae (OG) for CEmONC } \\
\text { facility and } \\
1 \mathrm{MO} \text { trained in Obstetrics and Gynae for the } \\
\text { BEmONC facility }\end{array}$ & \multicolumn{2}{|c|}{$\begin{array}{l}\text { Have full } \\
\text { human } \\
\text { resources } \\
\text { (2 MOs in } \\
\text { CEmONC and } 1 \\
\text { MO in } \\
\text { BEmONC) }\end{array}$} & $\begin{array}{l}\text { Have the } \\
\text { partial } \\
\text { human } \\
\text { resources } \\
\text { (1 MO in } \\
\text { CEmONC) }\end{array}$ & $\begin{array}{l}\text { Have no } \\
\text { MOs trained } \\
\quad \text { in OG }\end{array}$ \\
\hline 2. & $\begin{array}{l}\text { Have at least- } 1 \mathrm{MO} \text { trained in anesthesia and available } \\
\text { round the clock }\end{array}$ & & Yes & - & $\mathrm{No} / \mathrm{NA}$ \\
\hline 3. & $\begin{array}{l}\text { Have at least- } 1 \text { Pediatrician or an MO trained in new- } \\
\text { born care and IMCI }\end{array}$ & & Yes & - & No \\
\hline 4. & $\begin{array}{l}\text { Have adequate Staff Nurses ( } 6 \text { for comprehensive and } \\
3 \text { for basic facilities) available and trained in EOC and } \\
\text { infection prevention round the clock }\end{array}$ & & Yes & $\begin{array}{l}\text { Partially } \\
\text { available }\end{array}$ & No \\
\hline 5. & $\begin{array}{l}\text { Have a Lab Technician available and trained in blood } \\
\text { transfusion }\end{array}$ & & Yes & - & $\mathrm{No} / \mathrm{NA}$ \\
\hline 6. & $\begin{array}{l}\text { Have at least adequate Aya ( } 6 \text { for comprehensive and } 3 \\
\text { for basic facilities) available round the clock }\end{array}$ & & Yes & - & No \\
\hline \multicolumn{6}{|c|}{ Facility Management, Quality Monitoring and Death Review Committees } \\
\hline 7. & \multicolumn{2}{|l|}{$\begin{array}{l}\text { Hospital Management Committee is functional and held } \\
\text { meeting in the last one year (please see the meeting minutes) }\end{array}$} & Yes & - & No \\
\hline 8. & \multicolumn{2}{|l|}{$\begin{array}{l}\text { EOC Committee is functional and held meeting in the last } \\
\text { month (please see the meeting minutes) }\end{array}$} & Yes & - & No \\
\hline 9. & \multicolumn{2}{|l|}{$\begin{array}{l}\text { P4P and/or Coupon Committee is functional and held } \\
\text { meeting in the last month (please see the meeting minutes) }\end{array}$} & Yes & - & No \\
\hline 10. & \multicolumn{2}{|l|}{$\begin{array}{l}\text { Facility based death review committee is functional and held } \\
\text { meeting in the last month (if maternal or child death } \\
\text { occurred)- please see the reports }\end{array}$} & Yes & - & No \\
\hline 11. & \multicolumn{2}{|l|}{ Facility based Quality Assurance Teams have been formed } & Yes & - & No \\
\hline 12. & \multicolumn{2}{|l|}{$\begin{array}{l}\text { Facility based Quality Assurance Teams are functional (hold } \\
\text { meetings regularly) -please see the meeting minutes) }\end{array}$} & Yes & - & No \\
\hline \multirow[t]{2}{*}{13.} & \multicolumn{2}{|l|}{$\begin{array}{l}\text { Facility based Quality Assurance Teams uses monitoring } \\
\text { tools (please see the tools) }\end{array}$} & Yes & - & No \\
\hline & \multicolumn{2}{|c|}{ Total score $=$} & & & \\
\hline
\end{tabular}




\section{SECTION- B: INFRASTRUCTURE}

Table A.B. Qualitative indicators on infrastructure

\begin{tabular}{|c|c|c|c|}
\hline \multirow[t]{2}{*}{ S1 } & \multirow[t]{2}{*}{ Indicators (Fill in the score by observation/asking questions) } & \multicolumn{2}{|c|}{ Response Score } \\
\hline & & Yes-1 & No-0 \\
\hline \multicolumn{4}{|c|}{ Utility and facilities } \\
\hline 1. & Have running/potable water supply & 1 & 0 \\
\hline 2. & Have functional electricity supply & 1 & 0 \\
\hline 3. & Have functional generator (with adequate fuel supply) in the OT & 1 & 0 \\
\hline \multicolumn{4}{|c|}{ General cleanliness } \\
\hline 4. & $\begin{array}{l}\text { Surroundings of the facility are clean with no water logging or spread } \\
\text { of hospital waste }\end{array}$ & 1 & 0 \\
\hline 5. & Clean floors and no seepage from wall and ceiling & 1 & 0 \\
\hline 6. & Clean dust bins in all rooms, waiting area and corridor & 1 & 0 \\
\hline 7. & Clean toilets with water and soap & 1 & 0 \\
\hline \multicolumn{4}{|c|}{ Waiting area amenities } \\
\hline 8. & $\begin{array}{l}\text { Have an attendant to welcome and guide the patients or a visual aid } \\
\text { to inform the patients about service points }\end{array}$ & 1 & 0 \\
\hline 9. & Have benches in shaded area & 1 & 0 \\
\hline 10. & Have drinking water available for clients & 1 & 0 \\
\hline 11. & Have at least one separate toilet for women with soap and water & 1 & 0 \\
\hline \multicolumn{4}{|c|}{ Information and communication } \\
\hline 12. & Have Citizen's charter displayed in a prominent place & 1 & 0 \\
\hline 13. & $\begin{array}{l}\text { Have functional phone available for incoming calls (emergency } \\
\text { number) }\end{array}$ & 1 & 0 \\
\hline 14. & Have functional phone available for making outgoing calls & 1 & 0 \\
\hline 15. & $\begin{array}{l}\text { Have a functional vehicle with driver available for } 24 \text { hours for } \\
\text { referral }\end{array}$ & 1 & 0 \\
\hline 16. & Have flipchart(s) on EmONC issues & 1 & 0 \\
\hline 17. & Have brochures on EmONC issues & 1 & 0 \\
\hline 18. & Have flipchart(s) on family planning methods & 1 & 0 \\
\hline 19. & Have brochures on family planning methods & 1 & 0 \\
\hline \multicolumn{4}{|c|}{ Facilities } \\
\hline 20. & Emergency room has- trolley/stretcher/wheel chair & 1 & 0 \\
\hline 21. & Emergency room has-ward boy or someone to transfer patient & 1 & 0 \\
\hline 22. & Emergency room has- emergency drugs and IV solution & 1 & 0 \\
\hline
\end{tabular}




\begin{tabular}{|c|c|c|c|}
\hline \multirow[t]{2}{*}{ S1 } & \multirow[t]{2}{*}{ Indicators (Fill in the score by observation/asking questions) } & \multicolumn{2}{|c|}{ Response Score } \\
\hline & & Yes-1 & No-0 \\
\hline 23. & Emergency room has- examination table with privacy & 1 & 0 \\
\hline 24. & Emergency room has- BP instrument and stethoscope & 1 & 0 \\
\hline 25. & Emergency room has- Kidney basin & 1 & 0 \\
\hline 26. & Emergency room has- Tongue depressor & 1 & 0 \\
\hline 27. & Emergency room has- Thermometer with antiseptic lotion & 1 & 0 \\
\hline 28. & Emergency room has- Torch light & 1 & 0 \\
\hline 29. & Emergency room has- Hammer & 1 & 0 \\
\hline 30. & Emergency room has- Oral speculum & 1 & 0 \\
\hline 31. & Emergency room has- Sterile gloves & 1 & 0 \\
\hline 32. & Emergency room has- Vaginal speculum & 1 & 0 \\
\hline 33. & Emergency room has privacy for performing physical examination & 1 & 0 \\
\hline 34. & Labor room ensures- privacy and confidentiality & 1 & 0 \\
\hline 35. & $\begin{array}{l}\text { Labor room is environment friendly and cool with provision of } \\
\text { sound barrier (if possible) }\end{array}$ & 1 & 0 \\
\hline 36. & $\begin{array}{l}\text { Labor room has posters for-- what to expect in labor; postnatal care } \\
\text { including contraception and neonatal care including breastfeeding }\end{array}$ & 1 & 0 \\
\hline 37. & Labor room has- an attached toilet with water and soap & 1 & 0 \\
\hline 38. & Labor room has- provision for drinking water & 1 & 0 \\
\hline 39. & Labor room has- sitting arrangement for the attendant/companion & 1 & 0 \\
\hline 40. & $\begin{array}{l}\text { Labor room has- minimum number of labor tables ( } 2 \text { for the UHCs } \\
\text { and } 3 \text { for } \mathrm{DH} \text { ) and linen set }\end{array}$ & 1 & 0 \\
\hline 41. & Labor room has- provision for delivery in sitting position & 1 & 0 \\
\hline 42. & Labor room has- provision for spot light with spare bulbs & 1 & 0 \\
\hline 43. & Labor room has- screen & 1 & 0 \\
\hline 44. & Labor rooms has- at least 3 sterilized delivery sets/kits & 1 & 0 \\
\hline 45. & Labor rooms has- sucker machine & 1 & 0 \\
\hline 46. & Labor rooms has- sterilized gloves, gowns, gauze, cotton balls & 1 & 0 \\
\hline 47. & Labor rooms has- sterilized forceps set & 1 & 0 \\
\hline 48. & Labor rooms has- functioning vacuum extractor & 1 & 0 \\
\hline 49. & Labor rooms has- Episiotomy set (kit) & 1 & 0 \\
\hline 50. & Labor rooms has- MVA set with cannula (not applicable in $\mathrm{DH}$ ) & 1 & 0 \\
\hline 51. & Labor rooms has- $\mathrm{D} \& \mathrm{C}$ set & 1 & 0 \\
\hline 52. & Labor rooms has- working suction machine with suction tube & 1 & 0 \\
\hline
\end{tabular}




\begin{tabular}{|c|c|c|c|}
\hline \multirow[t]{2}{*}{ S1 } & \multirow[t]{2}{*}{ Indicators (Fill in the score by observation/asking questions) } & \multicolumn{2}{|c|}{ Response Score } \\
\hline & & Yes-1 & No-0 \\
\hline 53. & $\begin{array}{l}\text { Labor rooms has- mucus suckers for neonates- pedestal, hand } \\
\text { operation }\end{array}$ & 1 & 0 \\
\hline 54. & Labor rooms has- resuscitation tray for neonates & 1 & 0 \\
\hline 55. & $\begin{array}{l}\text { Labor rooms has- clean warm towel/cloths (at least } 3 \text { of } 3 \mathrm{ft} \times 2 \mathrm{ft} \text { ) } \\
\text { for neonates }\end{array}$ & 1 & 0 \\
\hline 56. & $\begin{array}{l}\text { Labor rooms has radiant warmer (electric) overhead type for } \\
\text { neonates }\end{array}$ & 1 & 0 \\
\hline 57. & Labor rooms has- room heater for neonates & 1 & 0 \\
\hline 58. & Labor rooms has- pediatric stethoscope for neonates & 1 & 0 \\
\hline 59. & Labor rooms has- sterile scissors to cut umbilical cord for neonates & 1 & 0 \\
\hline 60. & Labor rooms has- umbilical cord clamps, plastic for neonates & 1 & 0 \\
\hline 61. & $\begin{array}{l}\text { Labor rooms has- filled oxygen cylinder with carrier and key to open } \\
\text { cylinder valve }\end{array}$ & 1 & 0 \\
\hline 62. & Labor rooms has- emergency drugs & 1 & 0 \\
\hline 63. & Labor rooms has- antiseptics & 1 & 0 \\
\hline 64. & Labor rooms has- working BP apparatus, stethoscope, thermometer & 1 & 0 \\
\hline 65. & Labor rooms has- IV stands, IV needles and cannulas & 1 & 0 \\
\hline 66. & Labor rooms has- red buckets with cover for waste disposal & 1 & 0 \\
\hline 67. & Labor rooms has- box for sharp disposal & 1 & 0 \\
\hline 68. & Labor rooms has- racksine to cover labor bed & 1 & 0 \\
\hline 69. & Labor rooms has- draping sheets/gauze/cotton & 1 & 0 \\
\hline 70. & Labor rooms has- Ambu bag & 1 & 0 \\
\hline 71. & Labor rooms has- mouth gag & 1 & 0 \\
\hline 72. & Labor rooms has- trolley/wheel chair & 1 & 0 \\
\hline 73. & Labor rooms has- Ultrasonography (USG) machine & 1 & 0 \\
\hline 74. & Labor rooms has- bed pan & 1 & 0 \\
\hline 75. & Labor rooms has- set for craniotomy & 1 & 0 \\
\hline 76. & Labor rooms has- weight scale & 1 & 0 \\
\hline 77. & Labor rooms has- delivery register and protocols for EmONC & 1 & 0 \\
\hline 78. & Labor rooms has - partogram & 1 & 0 \\
\hline 79. & Labor rooms has - Continuous Cardiotocography (CTG) & 1 & 0 \\
\hline 80. & Labor rooms has - foetal doppler & 1 & 0 \\
\hline
\end{tabular}




\begin{tabular}{|c|c|c|c|}
\hline \multirow[t]{2}{*}{ S1 } & \multirow[t]{2}{*}{ Indicators (Fill in the score by observation/asking questions) } & \multicolumn{2}{|c|}{ Response Score } \\
\hline & & Yes-1 & No-0 \\
\hline 81. & Change/scrub room has- OT dress & 1 & 0 \\
\hline 82. & Change/scrub room has- OT shoes/shoe covers & 1 & 0 \\
\hline 83. & Change/scrub room has- caps and masks & 1 & 0 \\
\hline 84. & $\begin{array}{l}\text { Change/scrub room has- } 24 \text { hours running/available water and a } \\
\text { wash basin with elbow tap }\end{array}$ & 1 & 0 \\
\hline 85. & Change/scrub room has- scrub brushes and soap & 1 & 0 \\
\hline 86. & $\begin{array}{l}\text { District Hospital/ Comprehensive EmONC has } 1 \text { functional } \\
\text { operation theater - } \\
\text { - to conduct sterilization operation } \\
\text { - to provide anesthesia (CEmONC only) } \\
\text { - to conduct caesarean section (CEmONC only) }\end{array}$ & 1 & 0 \\
\hline 87. & Operation theater has- 3 sets of sterilized $\mathrm{C} / \mathrm{S}$ & 1 & 0 \\
\hline 88. & Operation theater has- sterilized linen packs & 1 & 0 \\
\hline 89. & Operation theater has- sterilized gloves, gowns, gauze, cotton balls & 1 & 0 \\
\hline 90. & Operation theater has- sterilized suction tubing & 1 & 0 \\
\hline 91. & Operation theater has- working OT light with spare OT table & 1 & 0 \\
\hline 92. & Operation theater has- working suction machine & 1 & 0 \\
\hline 93. & $\begin{array}{l}\text { Operation theater has- emergency drugs list with quantity and expiry } \\
\text { dates }\end{array}$ & 1 & 0 \\
\hline 94. & Operation theater has- resuscitator/Ambu bag & 1 & 0 \\
\hline 95. & $\begin{array}{l}\text { Operation theater has- laryngoscope with battery cells and spare } \\
\text { bulbs }\end{array}$ & 1 & 0 \\
\hline 96. & $\begin{array}{l}\text { Operation theater has- working anesthesia machine, spare oxygen } \\
\text { and nitrous oxide cylinders (filled) }\end{array}$ & 1 & 0 \\
\hline 97. & Operation theater has- list of anesthetic agents & 1 & 0 \\
\hline 98. & Operation theater has- spinal needle/epidermal kits & 1 & 0 \\
\hline 99. & Operation theater has- antiseptics & 1 & 0 \\
\hline 100. & $\begin{array}{l}\text { Operation theater has- working BP apparatus, stethoscope, } \\
\text { thermometer, IV stands, IV needles and cannula }\end{array}$ & 1 & 0 \\
\hline 101. & Operation theater has- MVA set with cannula & 1 & 0 \\
\hline 102. & Operation theater has- D \& C set & 1 & 0 \\
\hline 103. & Operation theater has- stretcher/trolley & 1 & 0 \\
\hline 104. & Operation theater has- on call staff- ready to perform emergency & 1 & 0 \\
\hline
\end{tabular}




\begin{tabular}{|c|c|c|c|}
\hline \multirow[t]{2}{*}{ S1 } & \multirow[t]{2}{*}{ Indicators (Fill in the score by observation/asking questions) } & \multicolumn{2}{|c|}{ Response Score } \\
\hline & & Yes-1 & No-0 \\
\hline & procedures within 30 minutes & & \\
\hline 105. & Operation theater - is clean after surgery & 1 & 0 \\
\hline 106. & Operation theater has- OT register & 1 & 0 \\
\hline 107. & Have fully equipped Post Operative room & 1 & 0 \\
\hline 108. & $\begin{array}{l}\text { Obstetric ward has - beds ready with mattresses, rubber sheet, and } \\
\text { clean bed sheets and pillows }\end{array}$ & 1 & 0 \\
\hline 109. & Obstetric ward has - bed side locker & 1 & 0 \\
\hline 110. & Obstetric ward has - bench chair for attendant & 1 & 0 \\
\hline 111. & $\begin{array}{l}\text { Obstetric ward has - emergency drugs and IVs in the medicine } \\
\text { cabinet }\end{array}$ & 1 & 0 \\
\hline 112. & $\begin{array}{l}\text { Obstetric ward has - working BP apparatus, stethoscope, } \\
\text { thermometer, IV stands, IV needles and cannulas }\end{array}$ & 1 & 0 \\
\hline 113. & $\begin{array}{l}\text { Obstetric ward has - filled oxygen cylinder with cylinder carrier (with } \\
\text { key to open the cylinder valve) and facemask }\end{array}$ & 1 & 0 \\
\hline 114. & Obstetric ward has - garbage bins/sharp disposal containers & 1 & 0 \\
\hline 115. & Obstetric ward has - staff prepared to handle emergency cases & 1 & 0 \\
\hline 116. & Obstetric ward has - indoor register & 1 & 0 \\
\hline 117. & Obstetric ward has - monthly reporting formats & 1 & 0 \\
\hline 118. & Obstetric ward is absolutely clean & 1 & 0 \\
\hline 119. & Obstetric ward's bathrooms are absolutely clean & 1 & 0 \\
\hline 120. & Pharmacy has- list of drugs placed for EmONC/ONC in pharmacy & 1 & 0 \\
\hline 121. & Pharmacy has- accurately maintained inventory register & 1 & 0 \\
\hline 122. & $\begin{array}{l}\text { Pharmacy has- qualified person on call to dispense necessary drugs } \\
24 \text { hours }\end{array}$ & 1 & 0 \\
\hline 123. & Pharmacy has- last stock balance prepared in the last week & 1 & 0 \\
\hline 124. & Store has- EmONC/ONC and FP registers & 1 & 0 \\
\hline 125. & $\begin{array}{l}\text { Store has- accurately maintained register for EmONC/ONC and FP } \\
\text { equipment, drugs, and accessories }\end{array}$ & 1 & 0 \\
\hline 126. & $\begin{array}{l}\text { Store has- timely supply of emergency drugs to emergency room, } \\
\text { OT, delivery room and wards }\end{array}$ & 1 & 0 \\
\hline 127. & $\begin{array}{l}\text { Autoclave room has- working autoclave machine with temperature } \\
\text { and pressure gauge }\end{array}$ & 1 & 0 \\
\hline 128. & Autoclave room has- indicator paper & 1 & 0 \\
\hline 129. & Autoclave room has- safe electric connection & 1 & 0 \\
\hline
\end{tabular}




\begin{tabular}{|c|l|c|c|}
\hline S1 & Indicators (Fill in the score by observation/asking questions) & \multicolumn{2}{|c|}{ Response Score } \\
\cline { 3 - 4 } & & Yes-1 & No-0 \\
\hline 130. & $\begin{array}{l}\text { Autoclave room has- table with marked areas- indicating space for } \\
\text { un-sterile and sterile areas }\end{array}$ & 1 & 0 \\
\hline 131. & Autoclave room has- register/log book & 1 & 0 \\
\hline 132. & Autoclave room has- trained persons for autoclaving & 1 & 0 \\
\hline & \multicolumn{1}{|r}{ Total score= } & & 0 \\
\hline
\end{tabular}

\section{SECTION- C: Laboratory}

Table A.C. Qualitative indicators on laboratory

\begin{tabular}{|c|l|c|c|}
\hline S1 & Indicators & \multicolumn{2}{|c|}{ Response Score } \\
\cline { 3 - 4 } & \multicolumn{1}{|c|}{ Yes-1 } & No-0 \\
\hline 1. & $\begin{array}{l}\text { Has adequate blood group testing and cross matching reagents and } \\
\text { blood collection items }\end{array}$ & 1 & 0 \\
\hline 2. & Has- blood collection bags & 1 & 0 \\
\hline 3. & Has- functional microscope & 1 & 0 \\
\hline 4. & Has facility for routine examination of stool & 1 & 0 \\
\hline 5. & Has facility for routine examination of urine & 1 & 0 \\
\hline 6. & $\begin{array}{l}\text { Has facility for routine examination of blood for TC, DC, ESR and } \\
\text { Hb\%. }\end{array}$ & 1 & 0 \\
\hline 7. & Has facility for blood grouping and cross matching & 1 & 0 \\
\hline 8. & Has facility for routine examination of sputum AFB & 1 & 0 \\
\hline 9. & Has registers for recording & 1 & 0 \\
\hline 10. & Has functioning refrigerator & & 0 \\
\hline 11. & Has on-call lab technician & & 0 \\
\hline & & & 1 \\
\hline
\end{tabular}




\section{SECTION- D: ESSENTIAL PROTOCOLS, GUIDELINES AND MIS}

Table A.D. Qualitative indicators on essential protocols, guidelines and MIS

\begin{tabular}{|l|l|c|c|}
\hline S1 & Indicators & \multicolumn{2}{|c|}{ Response Score } \\
\cline { 3 - 4 } & (Fill in the score by asking questions and observation) & 1 & Yes-1 \\
\hline 1. & Standard protocol for EmONC & 1 & 0 \\
\hline 2. & Standard protocol for IMCI & 1 & 0 \\
\hline 3. & Standard protocol for Infection prevention & 1 & 0 \\
\hline 4. & Standard protocol for Family planning (FP) & 1 & 0 \\
\hline 5. & Standard protocol for Quality Assurance & 1 & 0 \\
\hline 6. & Standard protocol for Death Review & 1 & 0 \\
\hline 7. & Management Information System (MIS) forms properly maintained & 1 & 0 \\
\hline 8. & Registers properly maintained & 1 & 0 \\
\hline 9. & P4P committee and Coupon Guidelines & 1 & 0 \\
\hline 10. & List of facility based QATs with the name of the members & 1 & 0 \\
\hline 11. & Monitoring tools to be practiced by the QATs & 1 & 0 \\
\hline 12. & Timely preparation and submission of MIS reports on EoC & & 0 \\
\hline 13. & Timely preparation and submission of MIS reports on IMCI & 1 & 0 \\
\hline 14. & Timely preparation and submission of MIS reports on FP & 1 & 0 \\
\hline & & Total score= & \\
\hline
\end{tabular}




\section{SECTION- E: EQUIPMENT AND SUPPLIES}

Table A.E. Qualitative indicators on essential equipment and supplies

\begin{tabular}{|c|c|c|c|}
\hline \multirow[t]{2}{*}{ S1 } & \multirow{2}{*}{$\begin{array}{l}\text { Indicators } \\
\text { (Fill in the score by asking questions and observation) }\end{array}$} & \multicolumn{2}{|c|}{ Response Score } \\
\hline & & Yes-1 & No-0 \\
\hline 1. & Anesthesia Machine & 1 & 0 \\
\hline 2. & Pulse Oximeter with monitor & 1 & 0 \\
\hline 3. & $\begin{array}{l}\text { Oxygen cylinders in OT, emergency room and indoor } \\
\text { (female and newborn's ward) }\end{array}$ & 1 & 0 \\
\hline 4. & Nitrous oxide cylinder & 1 & 0 \\
\hline 5. & Emergency light (torch? Generator? Solar powered?) & 1 & 0 \\
\hline 6. & Electric Sterilizer & 1 & 0 \\
\hline 7. & Sterilizer non electric & 1 & 0 \\
\hline 8. & Functioning Forceps & 1 & 0 \\
\hline 9. & Centre Spot Light & 1 & 0 \\
\hline 10. & Caesarean set (Number of sets) & 1 & 0 \\
\hline 11. & Delivery set & 1 & 0 \\
\hline 12. & Sucker machine & 1 & 0 \\
\hline 13. & Ambu bag & 1 & 0 \\
\hline 14. & Uterus Evacuation set & 1 & 0 \\
\hline 15. & Neonatal resuscitator & 1 & 0 \\
\hline 16. & Laryngoscope set & 1 & 0 \\
\hline 17. & Pump suction & 1 & 0 \\
\hline 18. & Sphygnomanometer (neonate, electronic) & 1 & 0 \\
\hline 19. & Hub cutter- Syringe, Mucus extractor & 1 & 0 \\
\hline 20. & I/V Cannula (24G/26G) & 1 & 0 \\
\hline 21. & Sterile equipments for cord cutting & 1 & 0 \\
\hline 22. & Feeding Tube & 1 & 0 \\
\hline 23. & Blood grouping and cross matching reagents & 1 & 0 \\
\hline 24. & Blood bag & 1 & 0 \\
\hline 25. & Doctor's gown, musk and cap & 1 & 0 \\
\hline 26. & Gloves & 1 & 0 \\
\hline 27. & $\begin{array}{l}\text { Rapid plasma reagin (RPR) kit, a blood test for syphilis or } \\
\text { Treponema pallidum hemagglutination (TPHA) test }\end{array}$ & 1 & 0 \\
\hline 28. & HIV Testing kit & 1 & 0 \\
\hline
\end{tabular}




\begin{tabular}{|c|c|c|c|}
\hline \multirow[t]{2}{*}{ S1 } & \multirow{2}{*}{$\begin{array}{l}\text { Indicators } \\
\text { (Fill in the score by asking questions and observation) }\end{array}$} & \multicolumn{2}{|c|}{ Response Score } \\
\hline & & Yes-1 & No-0 \\
\hline 29. & Hepatitis $\mathrm{B}$ and $\mathrm{C}$ virus testing kit & 1 & 0 \\
\hline 30. & Malaria screening reagent & 1 & 0 \\
\hline 31. & Haemoglobin test & 1 & 0 \\
\hline 32. & Complete Blood Count (CBC) & 1 & 0 \\
\hline 33. & Mobile Operating light & 1 & 0 \\
\hline 34. & Needle Spinal Ster Disp (EOC)- 22/ 27 gauge & 1 & 0 \\
\hline 35. & Umbilical cord clamp & 1 & 0 \\
\hline 36. & Bag, urine collection, $2000 \mathrm{ml}$ & 1 & 0 \\
\hline 37. & Folye's Catheter & 1 & 0 \\
\hline 38. & Cannula, 22G/24g, disposable & 1 & 0 \\
\hline 39. & Catheter, foley's-14,16 & 1 & 0 \\
\hline \multicolumn{4}{|c|}{ Medicine } \\
\hline 40. & Inj. Diazepam & 1 & 0 \\
\hline 41. & Inj. Ergometrin & 1 & 0 \\
\hline 42. & Inj. Oxytocin & 1 & 0 \\
\hline 43. & Tab. Misoprostol & 1 & 0 \\
\hline 44. & Inj. Magnesium Sulphate & 1 & 0 \\
\hline 45. & Inj. Adrenaline & 1 & 0 \\
\hline 46. & Inj. Ephidrine & 1 & 0 \\
\hline 47. & Inj. Aminophylline & 1 & 0 \\
\hline 48. & Inj. Hydrocortisone & 1 & 0 \\
\hline 49. & Anaesthetics and resuscitation drugs & 1 & 0 \\
\hline 50. & Inj. Pentothal & 1 & 0 \\
\hline 51. & Inj. Atropine & 1 & 0 \\
\hline 52. & Inj. Prostigmine & 1 & 0 \\
\hline 53. & Inj. Ketamine & 1 & 0 \\
\hline 54. & Inj. Xylocaine & 1 & 0 \\
\hline 55. & Inj. Flaxedil & 1 & 0 \\
\hline 56. & Ultracaine heavy & 1 & 0 \\
\hline 57. & Inj. Ciproprocin & 1 & 0 \\
\hline 58. & Inj. Gentamicine & 1 & 0 \\
\hline
\end{tabular}




\begin{tabular}{|c|c|c|c|}
\hline \multirow[t]{2}{*}{ S1 } & \multirow{2}{*}{$\begin{array}{l}\text { Indicators } \\
\text { (Fill in the score by asking questions and observation) }\end{array}$} & \multicolumn{2}{|c|}{ Response Score } \\
\hline & & Yes-1 & No-0 \\
\hline 59. & Suxamethorium & 1 & 0 \\
\hline 60. & Inj. Neostegmin & 1 & 0 \\
\hline 61. & Inj. Fentanyl & 1 & 0 \\
\hline 62. & Inj. Nocuron & 1 & 0 \\
\hline 63. & Sedil & 1 & 0 \\
\hline 64. & Normal saline & 1 & 0 \\
\hline 65. & Dextrose saline & 1 & 0 \\
\hline 66. & Hartman's Solution & 1 & 0 \\
\hline 67. & Plasma expanders & 1 & 0 \\
\hline 68. & Endotracheal tube & 1 & 0 \\
\hline 69. & Spinal needle & 1 & 0 \\
\hline 70. & Infusion set & 1 & 0 \\
\hline 71. & IV Canula & 1 & 0 \\
\hline 72. & Ceftriaxone, injection $250 \mathrm{mg} / 500 \mathrm{mg} / 1 \mathrm{~g} / 2 \mathrm{~g}$ & 1 & 0 \\
\hline 73. & Chloramphenicol, injection $1 \mathrm{~g}$ & 1 & 0 \\
\hline 74. & Chlorhexidine concentrate, $5 \%$ solution & 1 & 0 \\
\hline 75. & Chloroquine, tablets $150 \mathrm{mg}$ & 1 & 0 \\
\hline 76. & Cloxacillin, injection 500mg & 1 & 0 \\
\hline 77. & Co-trimoxazole, tablets $(400 \mathrm{mg}+80 \mathrm{mg})$ & 1 & 0 \\
\hline \multicolumn{4}{|c|}{ Medicine and equipment for children } \\
\hline 78. & ARI timer (functioning) & 1 & 0 \\
\hline 79. & Weight machine & 1 & 0 \\
\hline 80. & Feeding tube & 1 & 0 \\
\hline 81. & Nebulise solution & 1 & 0 \\
\hline 82. & ORS & 1 & 0 \\
\hline 83. & Cap-Vit A, Blue capsule & 1 & 0 \\
\hline 84. & Cap-Vit A, Red capsule & 1 & 0 \\
\hline 85. & Tab Paed- Co-trimoxazole $(120 \mathrm{mg}) /$ solution & 1 & 0 \\
\hline 86. & Tab- Co-trimoxazole (480 mg) & 1 & 0 \\
\hline 87. & Susp. Cotrimixazole & 1 & 0 \\
\hline 88. & Tab. Paracetamol & 1 & 0 \\
\hline
\end{tabular}




\begin{tabular}{|c|c|c|c|}
\hline \multirow[t]{2}{*}{ S1 } & \multirow{2}{*}{$\begin{array}{l}\text { Indicators } \\
\text { (Fill in the score by asking questions and observation) }\end{array}$} & \multicolumn{2}{|c|}{ Response Score } \\
\hline & & Yes-1 & No-0 \\
\hline 89. & Syp. Paracetamol & 1 & 0 \\
\hline 90. & Inj. Gentamicin (20mg) & 1 & 0 \\
\hline 91. & Inj. Gentamicin (80mg) & 1 & 0 \\
\hline 92. & Inj. Ampicilin (250mg) & 1 & 0 \\
\hline 93. & Inj. Benzyle penicillin (1 lac IU) & 1 & 0 \\
\hline 94. & Susp. Amoxycilin (bottle) & 1 & 0 \\
\hline 95. & Tab. Erythromycin (250 mg) & 1 & 0 \\
\hline 96. & Susp. Erythromycin (bottle) & 1 & 0 \\
\hline 97. & Cap. Tetracycline (250 mg) & 1 & 0 \\
\hline 98. & Cap. Doxicycline (100 mg) & 1 & 0 \\
\hline 99. & Erythromycin syrup, $50 \mathrm{mg} / \mathrm{kg}$ & 1 & 0 \\
\hline 100. & Ether anaesthetic & 1 & 0 \\
\hline 101. & Ferrous salt + folic acid, tablet $60 \mathrm{mg}+0.25 \mathrm{mg}$ & 1 & 0 \\
\hline 102. & Folic acid, tablet $1 \mathrm{mg}$ & 1 & 0 \\
\hline 103. & Calcium & 1 & 0 \\
\hline 104. & Furosemide $10 \mathrm{mg} / \mathrm{ml}$, injection $2 \mathrm{ml}$ & 1 & 0 \\
\hline 105. & Norethisterone, tablets $5 \mathrm{mg}$ & 1 & 0 \\
\hline & Total score $=$ & & \\
\hline
\end{tabular}

\section{SECTION- F: INFECTION PREVENTION PRACTICES}

\section{Table A.F. Qualitative indicators on infection prevention practices}

\begin{tabular}{|c|c|c|c|c|}
\hline \multirow[t]{2}{*}{ S1 } & \multirow{2}{*}{$\begin{array}{l}\text { Indicators } \\
\text { (Fill in the score by observing the providers } \\
\text { practicing following practices) }\end{array}$} & \multicolumn{3}{|c|}{ Response Score } \\
\hline & & 3 & 2 & $\mathbf{0}$ \\
\hline 1. & $\begin{array}{l}\text { Provider washed hands with soap and water and } \\
\text { wiped with personal towel/air dried }\end{array}$ & $\begin{array}{l}\text { Practiced in labor, } \\
\text { examination room } \\
\text { and OT }\end{array}$ & $\begin{array}{l}\text { Practiced } \\
\text { only in OT }\end{array}$ & Not practiced \\
\hline 2. & Providers wore gloves when required & $\begin{array}{l}\text { Practiced in } \\
\text { labor/ } \\
\text { examination } \\
\text { rooms and OT }\end{array}$ & $\begin{array}{l}\text { Practiced } \\
\text { only in OT }\end{array}$ & Not practiced \\
\hline 3. & Have autoclaved instruments & $\begin{array}{c}\text { In labor/ } \\
\text { examination } \\
\text { rooms and OT }\end{array}$ & only in OT & Not practiced \\
\hline
\end{tabular}




\begin{tabular}{|l|l|c|c|c|}
\hline S1 & Indicators & \multicolumn{3}{|c|}{ Response Score } \\
\cline { 3 - 5 } & $\begin{array}{l}\text { (Fill in the score by observing the providers } \\
\text { practicing following practices) }\end{array}$ & $\mathbf{3}$ & $\mathbf{2}$ & $\mathbf{0}$ \\
\hline 4. & Waste disposed of as per protocol & Well practiced & $\begin{array}{c}\text { Somewhat } \\
\text { practiced }\end{array}$ & Not practiced \\
\hline & & & & \\
\hline
\end{tabular}

SECTION- G: FAMILY PLANNING INCLUDING POST-PARTUM FAMILY PLANNING

Table A.G. Qualitative indicators on family planning including post-partum family planning

\begin{tabular}{|c|c|c|c|}
\hline \multirow[t]{2}{*}{ S1 } & \multirow{2}{*}{$\begin{array}{l}\text { Indicators } \\
\text { (Check the availability for at least } 20 \text { clients and interview/observe) }\end{array}$} & \multicolumn{2}{|c|}{ Response Score } \\
\hline & & Yes-1 & No-0 \\
\hline \multicolumn{4}{|c|}{ Contraceptive availability } \\
\hline 1. & Condoms- at least 200 pieces & 1 & 0 \\
\hline 2. & OCP- at least 20 cycles & 1 & 0 \\
\hline 3. & Injectables for 20 clients & 1 & 0 \\
\hline 4. & Implant for 20 clients & 1 & 0 \\
\hline 5. & IUDs for 20 clients & 1 & 0 \\
\hline 6. & ECP for 20 clients & 1 & 0 \\
\hline 7. & Availability of female sterilization services & 1 & 0 \\
\hline 8. & Availability of male sterilization services & 1 & 0 \\
\hline \multicolumn{4}{|c|}{ Counseling } \\
\hline 9. & $\begin{array}{l}\text { Informed clients about family planning methods to make informed } \\
\text { choice }\end{array}$ & 1 & 0 \\
\hline 10. & Counseled on during delivery contraceptive method options & 1 & 0 \\
\hline 11. & Counseled on post-delivery contraceptive method options & 1 & 0 \\
\hline 12. & Counseled on timing of use of post-delivery contraceptive methods & 1 & 0 \\
\hline 13. & Counseled how the method works and how it should be used & 1 & 0 \\
\hline 14. & Counseled on the side effects & & \\
\hline \multirow[t]{2}{*}{15.} & Counseled on side-effect management & 1 & 0 \\
\hline & Total score $=$ & & \\
\hline
\end{tabular}




\section{SECTION- H: EMERGENCY OBSTETRIC, NEWBORN AND UNDER -5 CHILDREN'S CARE}

Table A.H. Qualitative indicators on emergency obstetric, newborn and under $\mathbf{- 5}$ children's care

\begin{tabular}{|c|c|c|c|}
\hline \multirow[t]{2}{*}{ S1 } & \multirow{2}{*}{$\begin{array}{l}\text { Indicators } \\
\text { (Observe/interview) }\end{array}$} & \multicolumn{2}{|c|}{ Response Score } \\
\hline & & Yes-1 & No-0 \\
\hline 1. & Administer parental antibiotics to mother & 1 & 0 \\
\hline 2. & Administer utero-tonic drugs (Oxytocin) to mother & 1 & 0 \\
\hline 3. & $\begin{array}{l}\text { Administer anticonvulsant drug for eclampsia (magnesium } \\
\text { sulphate) }\end{array}$ & 1 & 0 \\
\hline 4. & Perform manual removal of placenta (after delivery) & 1 & 0 \\
\hline 5. & $\begin{array}{l}\text { Perform removal of retained product (manual vacuum } \\
\text { extraction, dilatation and curettage) (for delivery/post MR) }\end{array}$ & 1 & 0 \\
\hline 6. & $\begin{array}{l}\text { Perform assisted vaginal delivery like forceps delivery, vacuum } \\
\text { extraction) }\end{array}$ & 1 & 0 \\
\hline 7. & Perform blood transfusion with screening & 1 & 0 \\
\hline 8. & Use of Partograph & 1 & 0 \\
\hline 9. & $\begin{array}{l}\text { Active management of Third Stage Labor (AMTSL) } \\
\text { [Use of Oxytocin; Control cord traction; Uterine massage] }\end{array}$ & 1 & 0 \\
\hline 10. & Use of Oxytocin for management of PPH & 1 & 0 \\
\hline 11. & Compliance of EmONC service protocol & 1 & 0 \\
\hline 12. & Compliance of IMCI service protocol (not applicable in DH) & 1 & 0 \\
\hline 13. & Compliance of Infection prevention protocol & 1 & 0 \\
\hline 14. & Compliance of Hospital Waste Management protocol & 1 & 0 \\
\hline 15. & Waiting time less than 30 minutes for emergency patients & 1 & 0 \\
\hline 16. & Providers explain the procedures of diagnosis and treatment & 1 & 0 \\
\hline 17. & Respectful and non-judgmental interactions with clients & 1 & 0 \\
\hline 18. & Proper explanation to the clients & 1 & 0 \\
\hline 19. & Newborn care (drying, wrapping, breast feeding, care of U-Cord) & 1 & 0 \\
\hline 20. & Neonatal resuscitation with ambu-bag & 1 & 0 \\
\hline 21. & Asphyxia management (oximeter) & 1 & 0 \\
\hline 22. & Sepsis management for newborns (parental antibiotics) & 1 & 0 \\
\hline 23. & Low birth weight management (incubator, nasal-gastric tube) & 1 & 0 \\
\hline 24. & Photo therapy for jaundice & 1 & 0 \\
\hline 25. & Diarrhea with severe dehydration (treatment of dehydration and & 1 & 0 \\
\hline
\end{tabular}




\begin{tabular}{|c|l|c|c|}
\hline S1 & $\begin{array}{l}\text { Indicators } \\
\text { (Observe/interview) }\end{array}$ & Yes-1 & No-0 \\
\cline { 2 - 3 } & elyctrolyte imbalance) & 1 & 0 \\
\hline 26. & Severe pneumonia (parental antibiotics, oxygen) & 1 & 0 \\
\hline 27. & Sepsis management for under-5 (parental antibiotics) & 1 & 0 \\
\hline 28. & $\begin{array}{l}\text { Severe malnutrition } \\
\text { (Treatment of hypoglycaemia, hypothermia, dehydration; elyctrolyte } \\
\text { imbalance, correction of micronutrient deficiency, treatment of } \\
\text { infection, food supplementation; preparation of discharge) }\end{array}$ & & \\
\hline & \multicolumn{1}{|c|}{ Total score= } & & \\
\hline
\end{tabular}




\section{Appendix- B}

\section{Government of People's Republic of Bangladesh Directorate General of Health Services}

$$
\text { Reproductive Health Program }
$$

\section{Quality Assurance Group (QAG) Visit Quantitative Monitoring Tool for}

Pilot Study on Introducing Pay-For-Performance (P4P) Approach to

Increase Utilization of Maternal, Newborn and Child Health Services in Bangladesh

\begin{tabular}{llcc}
\hline S1. Services & $\begin{array}{c}\text { Numbers of Services } \\
\text { of the last } 3 \text { months }\end{array}$ & $\begin{array}{c}\text { Sources of } \\
\text { information }\end{array}$ \\
\hline
\end{tabular}

\section{Antenatal care}

1. Antenatal care

Institutional delivery

2. Normal delivery

3. Assisted vaginal delivery

(vacuum extraction, forceps)

4. Caesarean section

Delivery Complications Management, safe abortion and post abortion care

5. Removal of retained placenta/dilation and curettage $(\mathrm{D} \& \mathrm{C})$

6. Pre-eclampsia management

7. Eclampsia management

8. Ante-partum hemorrhage (APH)

9. $\quad$ Postpartum hemorrhage (PPH)

10. Post abortion care

11. Other obstetric-related operations

\section{Postnatal Care}

12. PNC within 24 hours

13. PNC within 42 days
- Monthly report of Obstetric Division

- Monthly report of DGFP (Form 4)

- Monthly report of Obstetric Division

- Monthly report of DGFP (Form 4)

- Monthly report of Obstetric Division
- Monthly report of Obstetric Division

- Monthly report of DGFP (Form 4) 


\begin{tabular}{llcc}
\hline S1. Services & $\begin{array}{c}\text { Numbers of Services } \\
\text { of the last } 3 \text { months }\end{array}$ & $\begin{array}{c}\text { Sources of } \\
\text { information }\end{array}$ \\
\hline
\end{tabular}

\section{Family planning}

14. Modern family planning method acceptance during delivery

- Monthly report of

DGFP (Form 4)

15. Modern family planning method acceptance within 42 days of delivery

16. Modern family planning method acceptance with post abortion care

\section{Newborn Care}

17. Newborn care (drying, wrapping, breast

feeding, care of U-Cord)

- Observation

Neonatal resuscitation with

18. Neonatal resu

19. Asphyxia management (oximeter)

20. Sepsis management (parental antibiotics)

21. Low birth weight management (incubator, nasal-gastric tube)

22. Photo therapy for jaundice

\section{Under-5 Children's Severe Case Management}

23. Diarrhea with severe dehydration (treatment

- Observation

of dehydration and elyctrolyte imbalance)

- IMCI Report

24. Severe pneumonia (parental antibiotics, oxygen)

25. Sepsis (parental antibiotics)

26. Severe malnutrition

Note: Operations, APH/PPH, sepsis management, low birth weight management, Photo therapy for jaundice and severe malnutrition are applicable to the comprehensive facilities only. 


\section{Amendment Pay-for-Performance (P4P) Incentive and Coupon Guideline on 2011}




\section{Annex A}

Issues/Concerns and Recommendations/Clarifications for Amendment to the

Pay-for- Performance (P4P) Incentive Guideline developed under the

Pilot Study on Introducing P4P Approach to Increase Utilization of

Maternal, Newborn and Child Health Services in Bangladesh

Table 1. Issues, Recommendations and Clarification for Amendment to the Table B.2. of the P4P Incentive Guideline

\begin{tabular}{|c|c|}
\hline Issues/Concerns & Recommendations/Clarification \\
\hline $\begin{array}{l}\text { In the Table B.2. on Target Beneficiaries } \\
\text { (Management) at District and Upazila levels: }\end{array}$ & $\begin{array}{l}\text { The following changes can be made, and } \\
\text { clarifications can be added to the Table B.2.: }\end{array}$ \\
\hline $\begin{array}{l}\text { 1. Both Civil Surgeon and Superintendent } \\
\text { positions are sometimes vacant. In that case } \\
\text { Deputy Civil Surgeon (DCS) or Medical } \\
\text { Officer Civil Surgeon (MO-CS) discharges } \\
\text { responsibility of a Civil Surgeon but they are } \\
\text { not included in the benefit package. }\end{array}$ & $\begin{array}{l}\text { 1. The person who gets the charge of a } \\
\text { Civil Surgeon will be included in the } \\
\text { benefit package in lieu of the Civil } \\
\text { Surgeon. The Civil Surgeon In-Charge's } \\
\text { level of effort will be } 100 \% \text {. }\end{array}$ \\
\hline $\begin{array}{l}\text { 2. The MO-CS position is not included in the } \\
\text { benefit package but s/he performs vital } \\
\text { communication activities for the } \mathrm{P} 4 \mathrm{P} \\
\text { incentive and project related information for } \\
\text { smooth functioning of the project. }\end{array}$ & $\begin{array}{l}\text { 2. The MO-CS is to be included as a } \\
\text { beneficiary from January-March } 2011 \text {, } \\
\text { and his/her level of effort will be } 50 \% \\
\text { only. MO-CS will be responsible for } \\
\text { smooth flow of communication related } \\
\text { to the P4P project. }\end{array}$ \\
\hline $\begin{array}{l}\text { 3. Upazila Health and Family Planning Officer } \\
\text { (UHFPO) and Upazila Family Planning } \\
\text { Officer (UFPO) positions are sometimes } \\
\text { vacant. }\end{array}$ & $\begin{array}{l}\text { 3. UHFPO In-charge and UFPO In- } \\
\text { charge will be included in lieu of } \\
\text { UHFPO and UFPO, respectively. Their } \\
\text { level of effort will be } 100 \% \text {. }\end{array}$ \\
\hline
\end{tabular}

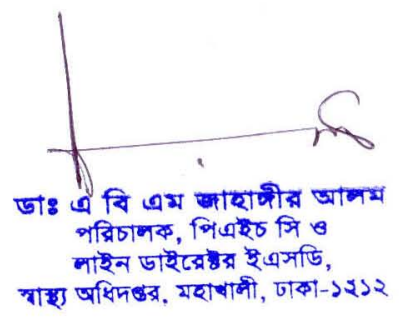


Table 2. Issues, Recommendations and Clatification for Amendment to the Table B.3. of the P4P Incentive Guideline for Direct and Indirect Providers of District Hospitals

\begin{tabular}{|c|c|}
\hline Issues/Concerns & Recommendations/Clarification \\
\hline $\begin{array}{l}\text { In the Table B.3. on Target Beneficiaries } \\
\text { (Service) at District Hospitals: }\end{array}$ & $\begin{array}{l}\text { The following changes can be made, and } \\
\text { clarifications can be added to the Table B.3.: }\end{array}$ \\
\hline $\begin{array}{l}\text { 1. Junior Consultant (Pediatrics) is not } \\
\text { included in the benefit package while } \\
\text { Junior Consultants have been playing the } \\
\text { major role in improving the performance } \\
\text { as a provider and a leader of the Quality } \\
\text { Assurance Team of the Pediatric Ward. } \\
\text { Besides, there is only Junior Consultant } \\
\text { position in some facilities. }\end{array}$ & $\begin{array}{l}\text { 1. Junior Consultant (Pediatrics) to be } \\
\text { included in the benefit package with } 100 \% \\
\text { level of effort. }\end{array}$ \\
\hline $\begin{array}{l}\text { 2. Emergency Medical Officer (EMO), and } \\
\text { MOs for Blood Bank, Gynecology \& } \\
\text { Pediatrics are included in the guideline. In } \\
\text { addition to the } 3 \text { EMOs to manage the } \\
\text { Emergency Room for } 24 \text { hours, at least } 6 \\
\text { MOs for Labor Room, OT, Obstetrics and } \\
\text { Pediatrics Wards are needed. The MOs do } \\
\text { not have adjectives defining their area of } \\
\text { work in their job title, while the Guideline } \\
\text { specifies MOs' title as MO (Gynecology } \\
\text { and Obstetrics) and so on. In some cases, } \\
\text { MOs are in-charge of Consultants; and }\end{array}$ & $\begin{array}{l}\text { 2. Emergency Medical Officer (EMO), and } \\
\text { MOs for Blood Bank, Gynecology \& } \\
\text { Pediattics are to be replaced with } 9 \mathrm{MO} \\
\text { positions-- } 3 \text { EMOs and } 6 \text { MOs for } \\
\text { managing the Labor Room, OT, Obstetrics } \\
\text { and Pediatrics Wards. The P4P and/or } \\
\text { Coupon Committee's clarification with } \\
\text { regard to distribution of responsibility of } \\
\text { MOs will ensure adherence to the } \\
\text { guideline. Assistant Surgeons, if plays role } \\
\text { in vital vacart position, can be included in } \\
\text { the package. }\end{array}$ \\
\hline
\end{tabular}
Assistant Surgeons on deputation are carrying out activities for the vital vacant posts.

3. Sr. Staff Nurse is included as a direct provider but there are other positions like Staff Nurse and Assistant Nurse performing the same job.

4. District Hospitals usually do not have providers from the Directorate General of Family Planning except for Jamalpur District Hospital. In this facility, a Sr. Family Welfare Visitor (Sr.FWV) is responsible for family planning counseling and services.

5. Consultant (Radiology) and Consultant (Pathology) are included in the package while the actual positions are Radiologist and Pathologist.

3. Positions, such as, Sr. Staff Nurse, Staff Nurse, Assistant Nurse will be interchangeable.

4. The Sr. FWV is to be included as a provider; and her level of effort will be $100 \%$.

5. Consultant (Radiology) and Consultant (Pathology) will be interchangeable with the terms Radiologist and Pathologist. 


\begin{tabular}{|c|c|}
\hline Issues/Concerns & Recommendations/Clarification \\
\hline $\begin{array}{l}\text { 6. Medical Technologist (Radiography) is } \\
\text { included in the approved Guideline, which } \\
\text { encompasses technologists for both X-ray } \\
\text { and ultrsonogram. Since X-ray is harmful } \\
\text { for pregnant women and newborns, only } \\
\text { Medical Technologist (ultrasonogram) was } \\
\text { supposed to be included in the guideline. } \\
\text { This error of generalization was rectified } \\
\text { later in the printed guideline. However, } \\
\text { according to the circulated guideline, the } \\
\text { facilities have already included Medical } \\
\text { Technologists (Radiography) for both X- } \\
\text { ray and ultrasonogram. }\end{array}$ & $\begin{array}{l}\text { 6. Medical Technologists (Radiography) for } \\
\text { both X-ray and ultrasonogram can be paid } \\
\text { incentives for October-December } 2010 \\
\text { quarter. However, from January } 2011 \text { only } \\
\text { the Medical Technologist (ultrasonogram) } \\
\text { will receive incentive. }\end{array}$ \\
\hline
\end{tabular}

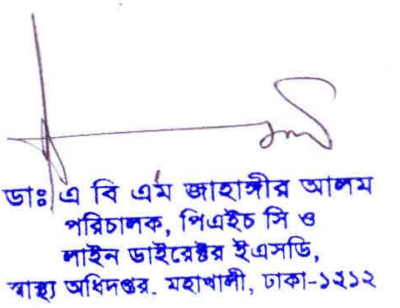


Table 3. Issues, Recommendations and Clarification for Amendment to the Table B.3. of the P4P Incentive Guideline for Administrative and Support Staff of District Hospitals

\begin{tabular}{|l}
\hline Issues/Concerns \\
(n the Table B.3. on Target Beneficiaries \\
1. Statistician position is included in the \\
guideline but there is no Statistician \\
position in the District Hospital. Office \\
Assistant keeps records and performs the \\
role of a statistician. Office Assistant also \\
assists in other administrative tasks. \\
However, for having the Statistician \\
position in the Guideline, a facility \\
included Statistician from the Civil \\
Surgeon's office in their MNCH team in \\
October-December 2010 .
\end{tabular}

2. All administrative staff's level of effort is $50 \%$. If a staff performs as a payment maker, then $50 \%$ level of effort is an under estimation of her/his actual effort.

Administrative staff category does not include Cashier. However, facilities sometimes include Cashier as a payment maker.

3. OT Boy and Sterilizer Operator are key support staff but inadvertently missed out from the guideline.

4. Ward Master has been inadvertently missed out from the guideline.

5. Junior Technician/Mechanic is vital position for maintenance of the facility utilities functional but this position is not included in the guideline.

6. Either Cook or Mashalchi is included in the guideline, but some facilities have both the positions.

7. In some cases, Domes perform the role of a Sweeper.

Recommendations/Clarification

The following changes can be made, and clarifications can be added to the Table B.3.:

1. Office Assistant position is to be added and her/his level of effort will be $50 \%$.

Statistician position is to be deleted but the Statistician who was included in OctoberDecember 2010 will receive incentive only for October-December 2010.

2. Administrative staff has been involved for assisting and performing financial operations, and their level of effort is $50 \%$.

However, the P4P and/or Coupon Committee may assign any staff as a payment maker whose total level of effort will be $100 \%$.

3. OT Boy and Sterilizer Operator are to be included with $100 \%$ level of effort.

4. Ward Master is to be included with $50 \%$ level of effort.

5. Junior Technician/Mechanic to be included as an indirect provider; and his/her level of effort will be $50 \%$.

6. Both Cook and Mashalchi are to be included.

7. Dome may be included as a Sweeper; and her/his level of effort will be 100\%.

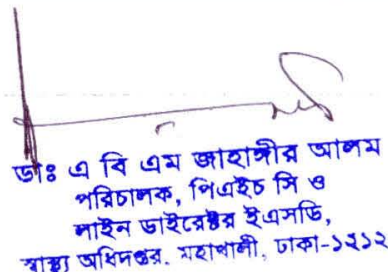


Table 4. Issues, Recommendations and Clarification for Amendment to the Table B.4. of the P4P Incentive Guideline for Direct and Indirect Providers of Upazila Health Complexes

\begin{tabular}{|c|c|}
\hline Issues/Concerns & Recommendations/Clarification \\
\hline $\begin{array}{l}\text { In the Table B.4. on Target Beneficiaries } \\
\text { (Service) at Upazila Health Complexes: }\end{array}$ & $\begin{array}{l}\text { The following changes can be made, and } \\
\text { clarifications can be added to the Table B.4.: }\end{array}$ \\
\hline $\begin{array}{l}\text { 1. In some facilities Assistant Surgeons are } \\
\text { carrying out activities for the vital vacant } \\
\text { posts. }\end{array}$ & $\begin{array}{l}\text { 1. Assistant Surgeons, if play role in the vital } \\
\text { vacant positions, can be included in the } \\
\text { MNCH team. }\end{array}$ \\
\hline $\begin{array}{l}\text { 2. Sr. Staff Nurse is included as a direct } \\
\text { provider but there are other positions like } \\
\text { Staff Nurse and Assistant Nurse } \\
\text { performing the same job. }\end{array}$ & $\begin{array}{l}\text { 2. Sr. Staff Nurse, Staff Nurse, and Assistant } \\
\text { Nurse positions are interchangeable. }\end{array}$ \\
\hline $\begin{array}{l}\text { 3. Medical Technologist (Radiography) is } \\
\text { included in the approved Guideline, which } \\
\text { encompasses technologists for both X-ray } \\
\text { and ultrsonogram. Since X-ray is harmful } \\
\text { for pregnant women and newborns, only } \\
\text { Medical Technologist (ultrasonogram) was } \\
\text { supposed to be included in the guideline. } \\
\text { This error of generalization was rectified } \\
\text { later in the printed guideline. However, } \\
\text { according to the circulated guideline, the } \\
\text { facilities have already included Medical } \\
\text { Technologist (Radiography) for both X- } \\
\text { ray and ultrasonogram. }\end{array}$ & $\begin{array}{l}\text { 3. Medical Technologists (Radiography) for } \\
\text { both X-ray and ultrasonogram can be paid } \\
\text { incentives for October-December } 2010 \\
\text { quarter. However, from January } 2011 \text { only } \\
\text { the Medical Technologist (ultrasonogram), } \\
\text { if available, will receive incentive. }\end{array}$ \\
\hline
\end{tabular}

Table 5. Issues, Recommendations and Clarification for Amendment to Table B.4. of the P4P Incentive Guideline for Administrative and Support Staff of Upazila Health Complexes

\begin{tabular}{|c|c|}
\hline Issues/Concerns & Recommendations/Clarification \\
\hline $\begin{array}{l}\text { In the Table B.4. on Target Beneficiaries } \\
\text { (Service) at Upazila Health Complexes: }\end{array}$ & $\begin{array}{l}\text { The following changes can be made, and } \\
\text { clarifications can be added to the Table B.4.: }\end{array}$ \\
\hline $\begin{array}{l}\text { 1. Office Assistant assists in administrative } \\
\text { tasks but not included in the guideline. }\end{array}$ & $\begin{array}{l}\text { 1. Office Assistant is to be added and } \\
\text { her } / \text { his level of effort will be } 50 \%\end{array}$ \\
\hline $\begin{array}{l}\text { 2. All administrative staff s level of effort is } \\
50 \% \text {. If a staff performs as a payment } \\
\text { maker, then } 50 \% \text { level of effort is an under } \\
\text { estimation of her/his actual effort. }\end{array}$ & $\begin{array}{l}\text { 2. Administrative staff has been involved } \\
\text { for assisting and performing financial } \\
\text { operations, and their level of effort is } \\
50 \% \text {. }\end{array}$ \\
\hline Administrative staff category does not & $\begin{array}{l}\text { However, the P4P and/or Coupon } \\
\text { Committee may assign any staff as a }\end{array}$ \\
\hline & 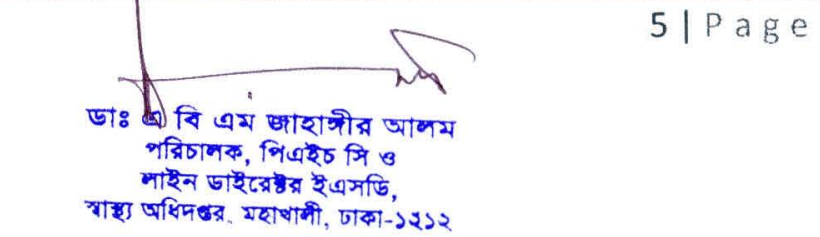 \\
\hline
\end{tabular}




\begin{tabular}{|c|c|}
\hline Issues/Concerns & Recommendations/Clarification \\
\hline $\begin{array}{l}\text { include Cashier. However, facilities } \\
\text { sometimes include Cashier as a payment } \\
\text { maker. }\end{array}$ & $\begin{array}{l}\text { payment maker whose total level of } \\
\text { effort will be } 100 \% \text {. }\end{array}$ \\
\hline $\begin{array}{l}\text { 3. OT Boy and Sterilizer Operator are key } \\
\text { support staff but inadvertently missed out } \\
\text { from the guideline. }\end{array}$ & $\begin{array}{l}\text { 3. OT Boy and Sterilizer Operator are to be } \\
\text { included with } 100 \% \text { level of effort. }\end{array}$ \\
\hline $\begin{array}{l}\text { 4. Ward Master has been inadvertently } \\
\text { missed out from the guideline. }\end{array}$ & $\begin{array}{l}\text { 4. Ward Master is to be included with } 50 \% \\
\text { level of effort. }\end{array}$ \\
\hline $\begin{array}{l}\text { 5. Junior Technician/Mechanic is vital } \\
\text { position for maintenance of the facility } \\
\text { utilities functional but this position is not } \\
\text { included in the guideline. }\end{array}$ & $\begin{array}{l}\text { 5. Junior Technician/Mechanic to be } \\
\text { included as an indirect provider; and } \\
\text { his/her level of effort will be } 50 \% \text {. }\end{array}$ \\
\hline $\begin{array}{l}\text { 6. Either Cook or Mashalchi is included in } \\
\text { the guideline, but some facilities have both } \\
\text { the positions. }\end{array}$ & $\begin{array}{l}\text { 6. Both Cook and Mashalchi are to be } \\
\text { included with } 50 \% \text { level of effort. }\end{array}$ \\
\hline $\begin{array}{l}\text { 7. In some cases, Domes perform the role of } \\
\text { a Sweeper. }\end{array}$ & $\begin{array}{l}\text { 7. Dome may be included as a Sweeper; } \\
\text { and her/his level of effort will be } 100 \% \text {. }\end{array}$ \\
\hline $\begin{array}{l}\text { 8. Aya of the Family Planning team is } \\
\text { important to achieve the family planning } \\
\text { targets, but they have not been included in } \\
\text { the guideline. }\end{array}$ & $\begin{array}{l}\text { 8. Aya of the Family Planning team at the } \\
\text { facility will be added from January-March } \\
2011 \text { quarter with } 100 \% \text { level of effort. }\end{array}$ \\
\hline
\end{tabular}

\section{Some General Clarification:}

- The P4P and/or Coupon Committees may include staff on deputation in the MNCH team in the role and capacities mentioned in the Guideline, but these persons will serve only against the sanctioned posts.

- The P4P project intends to award performance; thus, incentive is never automatic. For example, if someone is unable to contribute to the team effort for going on leave or for having a medical condition, in that case that/those person(s) are not eligible to receive incentives. If a person remains present sometimes in the facility, in that case, her/his incentives will be proportionate to her/his time. Similarly, if there is no ambulance or ultrasonogram machine, then the Ambulance Driver and the ultrasonogram technologist will not be eligible to receive incentives. ${ }^{1}$. The P4P and/or Coupon Committees are responsible to ensure making payment to the team members based on the performance of the individuals in attaining the institutional performance.

${ }^{1}$ It is expected that the facility head will exert his/her all out effort to make the ambulance and ultrasonogram machine functional as soon as possible.

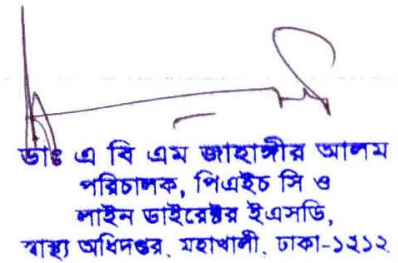


Table 6. Issues, Recommendations and Clarification for Amendment to the Table B.3. of the P4P Incentive Guideline

\begin{tabular}{|l|l|}
\hline Issues/Concerns & Recommendations/Clarification \\
\hline $\begin{array}{l}\text { In the Table B.3. on Target Beneficiaries } \\
\text { (Service) at District Hospitals: }\end{array}$ & $\begin{array}{l}\text { The following changes can be made, and } \\
\text { clarification can be added to the Table B.3.: }\end{array}$ \\
$\begin{array}{r}\text { 1. Medical Assistant is not included in the } \\
\text { benefit package while Medical Assistant } \\
\text { are providing services at the ANC \& } \\
\text { PNC corner in some District Hospital(s). }\end{array}$ & $\begin{array}{l}\text { 1. Maximum Two Medical Assistants } \\
\text { can be included for ANC \& PNC } \\
\text { corner, in the benefit package with } \\
100 \% \text { level of effort. }\end{array}$ \\
\hline
\end{tabular}

Table 7. Issues, Recommendations and Clarification for Amendment to the Table B.4. of the P4P Incentive Guideline

\begin{tabular}{|l|r|}
\hline Issues/Concerns & Recommendations/Clarification \\
\hline $\begin{array}{l}\text { In the Table B.4. on Target Beneficiaries } \\
\text { (Service) at District Hospitals: }\end{array}$ & $\begin{array}{l}\text { The following changes can be made, and } \\
\text { clarification can be added to the Table B.4.: }\end{array}$ \\
$\begin{array}{l}\text { 1. Nursing Supervisor is not included in the } \\
\text { benefit package of the incentive guideline } \\
\text { while they have been playing an } \\
\text { important role in Upazila Health } \\
\text { Complexes. }\end{array}$ & $\begin{array}{l}\text { 1. Nursing Supervisor to be included in } \\
\text { the benefit package with 50\% level of } \\
\text { effort as Administrative Staff. }\end{array}$ \\
\end{tabular}


Table 8. Issues, Recommendations and Clarification for Amendment to the Table E.1. of the Coupon Guideline

\begin{tabular}{|c|c|}
\hline Issues/Concerns & Recommendations/Clarification \\
\hline $\begin{array}{l}\text { In the Table E.1. on Types of services for } \\
\text { coupon beneficiaries: }\end{array}$ & $\begin{array}{l}\text { The following changes can be made, and } \\
\text { clarification can be added to the Table E.1.: }\end{array}$ \\
\hline $\begin{array}{l}\text { 1. Postnatal complications management } \\
\text { and a follow up service is included as } \\
\text { service for a coupon beneficiary. There is } \\
\text { no option for a normal postnatal care } \\
\text { (PNC) service, while it is very important } \\
\text { for a mother. }\end{array}$ & $\begin{array}{l}\text { 1. A normal PNC for a coupon } \\
\text { beneficiary to be included in the } \\
\text { benefit package against coupon for } \\
\text { the coupon holder. A beneficiary can } \\
\text { receive normal PNC service only for } \\
1 \text { time. }\end{array}$ \\
\hline
\end{tabular}

Table 9. Issues, Recommendations and Clarification for Amendment to the Table E.2. of the Coupon Guideline

\begin{tabular}{|l|r|}
\hline Issues/Concerns & Recommendations/Clarification \\
\hline $\begin{array}{l}\text { In the Table E.2. on Transportation coupon } \\
\text { amount according to types of services: }\end{array}$ & $\begin{array}{l}\text { The following changes can be made, and } \\
\text { clarification can be added to the Table E.2.: }\end{array}$ \\
$\begin{array}{l}\text { 1. Transportation amount for postnatal } \\
\text { complications management and a follow } \\
\text { up service is included in coupon } \\
\text { guideline for a coupon beneficiary. There } \\
\text { is no option for transportation amount } \\
\text { for a normal postnatal care (PNC) } \\
\text { service. }\end{array}$ & th for a normal PNC. \\
\hline
\end{tabular}


Annex B

Revised Beneficiaries, Level of Effort and Benefit Ratio and Revised Services against Coupon

Applicable from June, 2011

(Amendment Approved by the Directorate General of Health Services in June, 2011) 


\section{Target Beneficiaries at District and Upazila Level for P4P Project with Amendment from the Directorate General of Health Services, Ministry of Health and Family Welfare, \\ Government of Bangladesh}

(Applicable from June, 2011)

Table B.2. Target Beneficiaries (Management) at District and Upazila Levels

\begin{tabular}{lcr}
\hline Target beneficiaries & Level of effort (\%) & Benefit ratio \\
\hline Managers at District level & 100 & 100 \\
Civil Surgeon/Superintendent & 100 & 100 \\
Deputy Director, Family Planning & 100 & 100 \\
Medical Officer-Civil Surgeon (MO-CS) & & 50 \\
& 50 & 100 \\
Managers at Upazila level & & 100 \\
Upazila Health and Family Planning Officer (UHFPO) & 100 & 100 \\
Upazila Family Planning Officer (UFPO)/ & 100 & \\
Assistant Upazila Family Planning Officer (AUFPO) & 100 & \\
\hline
\end{tabular}

Note:

${ }^{1}$ MO-CS is responsible for smooth flow of P4P project related communications of the district. 
Table B.3. Target Beneficiaries (Service) at District Hospital

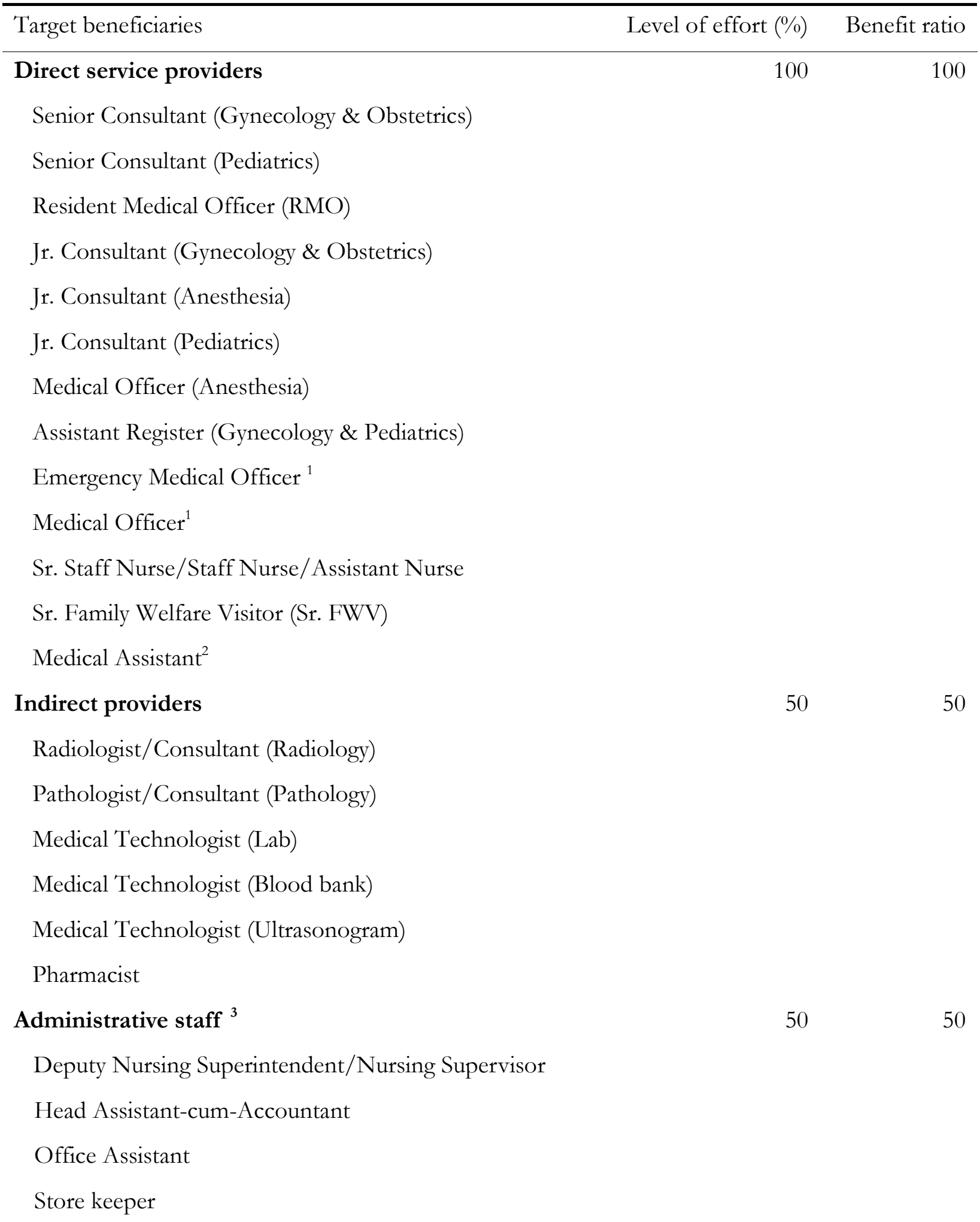




\begin{tabular}{lrr}
\hline Target beneficiaries & Level of effort $(\%)$ & Benefit ratio \\
\hline MLSS & & \\
Support staff & 100 & 100 \\
Aya & 100 & 100 \\
Ward Boy & 100 & 100 \\
OT Boy & 100 & 100 \\
Sterilizer Operator & 100 & 100 \\
Stretcher Bearer & 100 & 100 \\
Ambulance Driver & 100 & 100 \\
Sweeper/ Dome (as a Sweeper) & 50 & 50 \\
Ward Master & 50 & 50 \\
Junior Technician/Mechanic & 50 & 50 \\
Cook & 50 & 50 \\
Mashalchi & 50 & 50 \\
Security Guard & & \\
& & \\
\hline
\end{tabular}

Note:

1 Maximum 3 EMOs and 6 MOs for managing the Labor Room, OT, Obstetrics and Pediatrics wards will be the beneficiary.

2 All Medical Assistant who are working in emergency room/ward, ANC \& PNC Corner under P4P, will be the beneficiary.

${ }^{3}$ All administrative staff's level of effort is $50 \%$. The P4P and/or Coupon Committee may assign any staff as a payment maker, then his/her total level of effort will be $100 \%$. 
Table B.4. Target Beneficiaries (Service) at Upazila Health Complex

\begin{tabular}{|c|c|c|}
\hline Target beneficiaries & Level of effort $(\%)$ & Benefit ratio \\
\hline Direct providers & 100 & 100 \\
\hline \multicolumn{3}{|l|}{ Jr. Consultant (Gynecology \& Obstetric) } \\
\hline \multicolumn{3}{|l|}{ Jr. Consultant (Pediatrics) } \\
\hline \multicolumn{3}{|l|}{ Jr. Consultant (Anesthesia)/Medical Officer (Anesthesia) } \\
\hline \multicolumn{3}{|l|}{ Medical Officer (MCH-FP) } \\
\hline \multicolumn{3}{|l|}{ Resident Medical Officer } \\
\hline \multicolumn{3}{|l|}{ Medical Officer } \\
\hline \multicolumn{3}{|l|}{ Medical Officer (Disease Control) ${ }^{1}$} \\
\hline \multicolumn{3}{|l|}{ Assistant Surgeons } \\
\hline \multicolumn{3}{|l|}{ Sr. Staff Nurse/Staff Nurse/Assistant Nurse } \\
\hline \multicolumn{3}{|l|}{ Assistant Family Welfare Officer/Sr. Family Welfare Visitor } \\
\hline \multicolumn{3}{|l|}{ Family Welfare Visitor } \\
\hline \multicolumn{3}{|l|}{ Medical Assistant ${ }^{1}$} \\
\hline Indirect providers & 50 & 50 \\
\hline \multicolumn{3}{|l|}{ Pathologist } \\
\hline \multicolumn{3}{|l|}{ Medical Technologist (Ultrasonogram) } \\
\hline \multicolumn{3}{|l|}{ Medical Technologist (Lab) } \\
\hline \multicolumn{3}{|l|}{ EPI Technician } \\
\hline \multicolumn{3}{|l|}{ Pharmacist } \\
\hline Administrative staff ${ }^{2}$ & 50 & 50 \\
\hline \multicolumn{3}{|l|}{ Nursing Supervisor } \\
\hline \multicolumn{3}{|l|}{ Head Assistant-cum-Accountant } \\
\hline \multicolumn{3}{|l|}{ Statistician } \\
\hline \multicolumn{3}{|l|}{ Office Assistant } \\
\hline \multicolumn{3}{|l|}{ Store keeper } \\
\hline MLSS & & \\
\hline
\end{tabular}




\begin{tabular}{lrr}
\hline Target beneficiaries & Level of effort $(\%)$ & Benefit ratio \\
\hline Support staff & 100 & 100 \\
Aya & 100 & 100 \\
Ward Boy & 100 & 100 \\
OT Boy & 100 & 100 \\
Sterilizer Operator & 100 & 100 \\
Stretcher Bearer & 100 & 100 \\
Ambulance Driver & 100 & 100 \\
Sweeper/Dome (as a Sweeper) & 50 & 50 \\
Ward Master & 50 & 50 \\
Junior Technician/Mechanic & 50 & 50 \\
Cook & 50 & 50 \\
Mashalchi & 50 & 50 \\
Security Guard & &
\end{tabular}

1 All Medical Assistant who are working in emergency room/ward, ANC \& PNC Corner under P4P, will be the beneficiary.

2 All administrative staff's level of effort is $50 \%$. If, the P4P and/or Coupon Committee assign any staff as a payment maker, then his/her total level of effort will be $100 \%$.

\section{Some General Clarification:}

- The P4P and/or Coupon Committees may include staff on deputation, for example, Assistant Surgeons, in the MNCH team in role and capacities mentioned in the Guideline, but these persons will serve only against the sanctioned posts.

- The P4P project intends to award performance; thus, incentive is never automatic. For example, if someone is unable to contribute to the team effort for going on leave or for having a medical condition, in that case that/those person(s) are not eligible to receive incentives. If a person remains present sometimes in the facility, in that case, her/his incentives will be proportionate to her/his time. Similarly, if there is no ambulance or ultrasonogram machine, then the Ambulance Driver and the ultrasonogram technologists will not be eligible to receive incentives ${ }^{1}$. The P4P and/or Coupon Committees are responsible to ensure making payment to the team members based on the performance of the individuals in attaining the institutional performance.

\footnotetext{
${ }^{1}$ It is expected that the facility head will exert his/her all out effort to make the ambulance and ultrasonogram machine functional as soon as possible.
} 
Types of the Coupon at Health Facilities for Coupon Beneficiaries for P4P Project with Amendment from the Directorate General of Health Services, Ministry of Health and Family Welfare, Government of Bangladesh

(Applicable from July, 2011)

Table E.1. Types of services for which beneficiaries will receive coupon

\begin{tabular}{ll}
\hline Purpose & Frequency \\
\hline Antenatal care & 4 times \\
Pregnancy complications management & 1 time \\
Delivery & 1 time \\
One Postnatal Care or One Postnatal complications management and one & 2 times \\
follow up service for complications ${ }^{1}$ & \\
$\begin{array}{l}\text { Neonate's (less than } 28 \text { days olds) complications management and a follow } \\
\text { up service }\end{array}$ & 2 times \\
Under-five child's complications management and a follow up service & 2 times
\end{tabular}

\section{Note:}

${ }^{1}$ Pregnancy complications management will also include safe abortion care, and post-abortion care services.

2 If a beneficiary received one PNC, then she can receive only a Postnatal complications management and will not eligible for a follow up visit. On the other hand if a beneficiary received one Postnatal complications management service she can receive one follow up visit and will not eligible for a regular PNC. 
Table E.2. Transportation coupon amount according to types of services

\begin{tabular}{|c|c|c|c|}
\hline \multicolumn{2}{|c|}{ Purpose } & \multirow{2}{*}{$\begin{array}{l}\text { Frequency } \\
4 \text { times }\end{array}$} & \multirow{2}{*}{$\begin{array}{l}\text { Amount per visit } \\
\text { (Taka) } \\
100\end{array}$} \\
\hline 1. & Antenatal care & & \\
\hline 2. & Pregnancy complications management & 1 time & $300-700$ \\
\hline 3. & Delivery & 1 time & $300-700$ \\
\hline 4. & $\begin{array}{l}\text { One Postnatal Care or One Postnatal complications } \\
\text { management and one follow up service for } \\
\text { Complications }^{*}\end{array}$ & 2 times & $100 / 300-700$ \\
\hline 5. & $\begin{array}{l}\text { Neonate's (less than } 28 \text { days olds) complications } \\
\text { management and a follow-up service }\end{array}$ & 2 times & $300-700$ \\
\hline 6. & $\begin{array}{l}\text { Under-five child's complications management } \\
\text { and a follow-up service }\end{array}$ & 2 times & $300-700$ \\
\hline
\end{tabular}

Note: The P4P and Coupon Committee will decide the amount of transport within the limit according to distance.

* A beneficiary who received the normal PNC, she will get 100 taka as transportation cost and a beneficiary who received Postnatal Complications Management and follow up service for complications will get 300-700 taka as transportation. 


\section{Annex C}

\section{Revised Incentive Guideline for Fieldworkers}

Applicable from August, 2011

(Amendment Approved by the Directorate General of Health Services in August, 2011) 
Issues/Concerns and Recommendations/Clarifications for Amendment to the

Pay-for-Performance (P4P) Incentive Guideline developed under the

Pilot Study on Introducing P4P Approach to Increase Utilization of

Maternal, Newborn and Child Health Services in Bangladesh

Issues recommendation and Clarification for Amendment to the B.8 of the P4P Incentives Guideline for District and Indirect Providers of District Hospitals

\begin{tabular}{|l|l|}
\hline Issues/ Concerns & Recommendations/ Clarification \\
\hline In B.8 on Incentives amount at P4P facilities: & $\begin{array}{l}\text { The following changes can be made and } \\
\text { clarification can be added to the B.8 }\end{array}$ \\
$\begin{array}{l}\text { The referees (field workers) will receive Taka } \\
\text { refor each successful referral. The successful } \\
\text { referred client from the facility, which is to be } \\
\text { documented with referral slips and registers. }\end{array}$ & $\begin{array}{l}\text { The referees (field workers) will receive Taka } \\
150 \text { for each successful referral. The successful } \\
\text { referral connotes receiving services by the } \\
\text { referred client from the facility, which is to be } \\
\text { documented with referral slips and registers. }\end{array}$ \\
& $\begin{array}{l}\text { In the same area BRAC provide } 150 \text { th to their } \\
\text { field workers for assisting home delivery and their } \\
\text { amount of incentives discourages filed workers to } \\
\text { motivate pregnant mother for institutional } \\
\text { delivery. }\end{array}$ \\
\hline
\end{tabular}

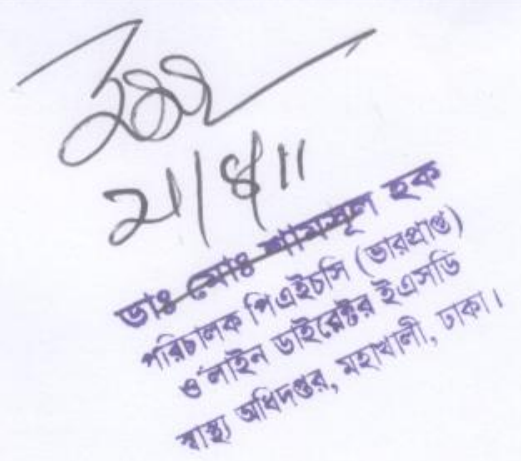


